\title{
Hitchhiking Nanoparticles: Reversible Coupling of Lipid-Based Nanoparticles to Cytotoxic T Lymphocytes
}

Laura Wayteck ${ }^{a}$, Heleen Dewitte ${ }^{a}$, Lynn De Backer ${ }^{a}$, Karine Breckpot ${ }^{b}$, Jo Demeester ${ }^{a}$, Stefaan C. De Smedt $t^{a, *}$, Koen Raemdonck $k^{a, \S}$

${ }^{a}$ Laboratory of General Biochemistry and Physical Pharmacy, Faculty of Pharmaceutical Sciences, Ghent University, Ottergemsesteenweg 460, 9000 Ghent, Belgium

${ }^{b}$ Laboratory of Molecular and Cellular Therapy, Department of Biomedical Sciences, Vrije Universiteit Brussel, Laarbeeklaan 103/E, 1090 Brussels, Belgium

$\S$ Both authors contributed equally to this work

*Corresponding author at: Laboratory of General Biochemistry and Physical Pharmacy, Ottergemsesteenweg 460, 9000 Ghent, Belgium. Tel.:+32 926480 76; fax: +32 92648189 . E-mail address: $\underline{\text { Stefaan.Desmedt@Ugent.be }}$ 
Keywords: cell-mediated drug delivery, tumor targeting, cytotoxic T lymphocytes, nanoparticles, liposomes

\section{Abstract}

Following intravenous injection of anti-cancer nanomedicines, many barriers need to be overcome en route to the tumor. Cell-mediated delivery of nanoparticles (NPs) is promising in terms of overcoming several of these barriers based on the tumoritropic migratory properties of particular cell types. This guided transport aims to enhance the NP accumulation in the tumor and moreover enhance the infiltration of regions that are typically inaccessible for free NPs. Within this study, cytotoxic $\mathrm{CD}^{+} \mathrm{T}$ cells were selected as carriers based on both their ability to migrate to the tumor and their intrinsic cytolytic activity against tumor cells. Many anti-cancer nanomedicines require tumor cell internalization to mediate cytosolic drug delivery and enhance the anti-cancer effect. This proof-of-concept therefore reports on the reversible attachment of liposomes to the surface of cytotoxic $\mathrm{T}$ lymphocytes via a reduction sensitive coupling. The activation status of the $\mathrm{T}$ cells and the liposome composition are shown to strongly influence the loading efficiency. Loading the cells with liposomes does not compromise $\mathrm{T}$ cell functionalities like proliferation and cytolytic function. Additionally, the triggered liposome release is demonstrated upon the addition of glutathione. Based on this optimization using liposomes as model NPs, a small interfering RNA (siRNA)-loaded NP was developed that can be coupled to the surface of $\mathrm{CD} 8^{+} \mathrm{T}$ cells. 


\section{Introduction}

Nanoparticles (NPs) have been widely investigated for the delivery of anti-cancer drugs to tumor tissues [1-3]. Although a lot of research has been performed, to date, only few nanomedicines are in clinical use for the treatment of cancer $[4,5]$. One of the key challenges is inadequate targeted delivery of drug-loaded NPs to the tumor tissue following systemic administration. A critical barrier remains the vascular endothelium which controls the extravasation of NPs from the bloodstream into the target tissue [6, 7]. Because NP extravasation is dependent on the size of fenestrae, tumor tissue may favor this delivery route by its leaky blood vasculature. This increased extravasation in combination with the poor lymphatic drainage found in tumors results in the accumulation of NPs in the tumor tissue and is also known as the enhanced permeation and retention (EPR) phenomenon [8]. Unfortunately, the widespread application of the EPR-based passive targeting of tumors is hampered by the heterogeneity in tumor vasculature both within a single tumor and between different tumor types [9].

Besides relying on passive targeting alone, nanomedicines are frequently modified with a targeting ligand that specifically recognizes a receptor that is present on or overexpressed by tumor cells. Several studies have shown that this active targeting strategy enhances the internalization in the target cells, albeit without increasing the accumulation in the tumor tissue after systemic delivery [10-12]. Furthermore, it was observed that active targeting can hinder the diffusion of NPs into the tumor tissue due to the binding-site barrier phenomenon in which particles mainly bind to perivascular cells [1].

One alternative strategy that might overcome these targeting limitations is cell-mediated delivery $[13,14]$. Certain cell types have the intrinsic ability to cross the endothelial barrier and infiltrate the tumor tissue, which makes them attractive carriers for NP delivery [15]. Moreover, tumors contain hypoxic and necrotic regions that are typically not easily accessible 
for NPs, leading to incomplete tumor regression [16, 17]. Monocytes and macrophages have already been investigated as carriers for the delivery of NPs in these low accessible regions [18-20]. Also T cells have the intrinsic ability to migrate to the tumor tissue. Moreover, cytotoxic $\mathrm{CD}^{+} \mathrm{T}$ lymphocytes (CTLs) have the added advantage of exerting a cytotoxic effect on tumor cells upon their recognition and binding of tumor-associated antigens. By virtue of these specific traits, the adoptive transfer of $\mathrm{T}$ cells is a widely investigated cancer immunotherapy. Adoptive T cell therapy can be described as the transfer of ex vivo selected and expanded tumor-reactive $\mathrm{T}$ cells [21]. Although adoptive $\mathrm{T}$ cell therapy already showed impressive clinical outcomes, complete tumor regression was only observed in a restricted number of patients mainly due to the immunosuppressive tumor microenvironment and also the loss of tumor antigens to which the therapy was targeted [22, 23]. Therefore, strategies combining conventional chemotherapies with cancer immunotherapy have gained interest in recent years [24].

The use of T cells as NP carrier cells has been assessed previously by Irvine and colleagues, who irreversible attached drug-loaded NPs to their surface and also by Vile and co-workers, who exploited $\mathrm{T}$ cells for the intratumoral delivery of therapeutic viral vectors [25-27]. Here, we propose a synergistic strategy based on CTLs that serve a dual purpose, i.e. induce a direct killing effect on tumor cells and enhance the delivery of drug-loaded NPs into tumor tissue, which may kill $\mathrm{T}$ cell-refractory tumor cells. To this end, we investigated the covalent attachment of NPs to the surface of CTLs. Moreover, we envisioned the triggered release of the cell surface-conjugated NPs in the tumor microenvironment which could allow their subsequent internalization by target tumor cells and hence a more efficient delivery of anticancer drugs. This concept is of particular interest for charged macromolecular therapeutics that are membrane-impermeable such as small interfering RNA (siRNA), which require NPmediated cytosolic delivery in target cells. To date, a reversible coupling strategy of NPs to the surface of CTLs has not yet been investigated. 
Given their outstanding promise and versatility as drug delivery systems, we used liposomes as model nanomedicines within this proof-of-concept [28]. First, it was assessed whether liposomes can be attached to the surface of CTLs based on disulfide bond formation between exofacial thiols present on the CTL plasma membrane and thiol-reactive liposomes. Next, we showed the triggered release of liposomes in the presence of glutathione as a reducing agent. Importantly, in vitro data indicated that the NP-load did not affect the $\mathrm{T}$ cell functionalities such as proliferation and cytotoxic effector functions.

It has been demonstrated that the adoptive transfer of less differentiated $\mathrm{T}$ cells is associated with superior persistence and anti-tumor responses compared to the more differentiated effector T cells $[29,30]$. On the other hand, the differentiation of naive T cells into $\mathrm{CD} 8^{+}$ effector T cells is required for their migratory and cytotoxic function. Since both activated and naive $\mathrm{T}$ lymphocytes are investigated for adoptive $\mathrm{T}$ cell therapy, we therefore evaluated the reversible coupling of liposomes as a function of their activation status [31].

Finally, building further on this optimized reversible coupling strategy, we demonstrated the coupling of lipid-enveloped nanogels, loaded with siRNA, to the surface of activated CD8 ${ }^{+} \mathrm{T}$ cells. 


\section{Materials and Methods}

\section{Preparation of liposomes and characterization:}

The liposomes were composed of 1,2-dioleoyl-sn-glycero-3-phosphocholine (DOPC), egg phosphatidylglycerol (egg PG) or 18:1 1,2-dioleoyl-sn-glycero-3-phosphoethanolamine-N-[3(2-pyridyldithio)propionate] (PE-PDP), and the fluorescent 1,1'-dioctadecyl-3,3,3',3'tetramethylindodicarbocyanine (DiD). DOPC and PE-PDP lipids were purchased from Avanti Polar Lipids (Alabaster, AL), PG lipids from Lipoid (Ludwigshafen, Germany), and DiD from Molecular probes (Invitrogen, Merelbeke, Belgium). The typical liposome composition comprised $50 \mathrm{wt} \%$ PE-PDP or PG, 3 wt $\%$ DiD, and $47 \mathrm{wt} \%$ DOPC. When varying the PEPDP or PG content, the fraction of DOPC lipids was adjusted accordingly. To form the liposomes, a lipid mixture in chloroform was prepared and pipetted in a round-bottom glass flask, followed by evaporation of the chloroform solvent to form a thin lipid film. The dried lipids were rehydrated in phosphate buffered saline (PBS; Gibco-Invitrogen, Merelbeke, Belgium) at ambient temperature followed by an extrusion of the resultant multilamellar liposomes through a $200 \mathrm{~nm}$ polycarbonate filter (Whatman, Diegem, Belgium). Liposome size and surface charge were measured in HEPES buffer $(20 \mathrm{mM}, \mathrm{pH} 7.4)$ at $25^{\circ} \mathrm{C}$ by dynamic light scattering and zeta potential measurements, respectively, using a Zetasizer Nano ZS (Malvern, UK) equipped with Dispersion Technology Software (DTS).

\section{Cell culture:}

$\mathrm{CD}^{+} \mathrm{T}$ cells were isolated from the spleen of OT-I mice using a negative isolation $\mathrm{CD} 8^{+}$kit (stem cell technologies, Grenoble, France). Cells were activated with anti-CD3/CD28 Dynabeads $^{\circledR}$ (Gibco-Invitrogen) at a density of $2 \times 10^{6}$ cells/well and a bead-to-cell ratio of 1:1 in a 24-well plate. The cells were cultured in complete $\mathrm{T}$ cell culture medium containing advanced RPMI medium (Gibco-Invitrogen) supplemented with 10\% fetal bovine serum (FBS; Hyclone, Thermo Scientific, MA, USA), 2 mM L-glutamine (Gibco-Invitrogen), 1\% 
penicillin/streptomycin (Gibco-Invitrogen). According to the manufacturer's protocol $30 \mathrm{U} \mathrm{ml}^{-1} \mathrm{rIL}-2$ (Miltenyi Biotec, Leiden, The Netherlands) was added to the culture medium and restimulation was performed by adding new beads every 7 days.

The mouse thymoma cell lines EL4 and E.G7-OVA were purchased from the American Type Culture Collection (ATCC). The E.G7-OVA cell line is an EL4 cell line that was stably transfected with the plasmid pAc-neo-OVA, which carries a complete copy of chicken ovalbumine (OVA) mRNA. Both cell lines were cultivated in RPMI 1640 (Gibco-Invitrogen) supplemented with $10 \% \mathrm{FBS}, 2 \mathrm{mM}$ L-glutamine, and $1 \%$ penicillin/streptomycin.

\section{Visualization of exofacial thiol groups:}

$\mathrm{CD}^{+} \mathrm{T}$ cells were incubated for $15 \mathrm{~min}$ with $100 \mu \mathrm{g} \mathrm{ml}^{-1}$ Cy5-labeled maleimide (GE Healthcare Life Sciences, Diegem, Belgium) at room temperature. After washing the cells with PBS, the cells were fixed with $4 \%$ paraformaldehyde (Sigma-Aldrich, Bornem, Belgium). Confocal microscopy images were acquired using a Nikon C1si confocal laser scanning microscope (Nikon Benelux, Brussels, Belgium) equipped with a Plan Apo VC 60x 1.4 NA oil immersion objective lens (Nikon). The Cy5 dye was excited with a $636 \mathrm{~nm}$ diode laser (CVI Melles Griot, NM, USA).

Reversible coupling of liposomes to the surface of $\mathrm{CD}^{+} \mathrm{T}$ cells:

$\mathrm{CD}^{+} \mathrm{T}$ cells $\left(3 \times 10^{5}\right.$ cells per sample) were incubated in serum-free advanced RPMI with the liposomes during $1 \mathrm{~h}$ at $37^{\circ} \mathrm{C}$ with gentle mixing after $30 \mathrm{~min}$. A liposome concentration of $2 \mathrm{mg} \mathrm{ml}^{-1}$ lipids was used, if not indicated differently. Subsequently, the cells were washed with PBS (supplemented with 5\% FBS) and to discriminate the $\mathrm{CD} 8^{+}$population the cells were stained with a CD8-AlexaFluor488 antibody (BD Pharmingen, Erembodegem, Belgium) for $30 \mathrm{~min}$ at room temperature in PBS (supplemented with 5\% FBS). The amount of liposomes attached to the $\mathrm{CD}^{+} \mathrm{T}$ cells was quantified via flow cytometry by measuring the DiD (red) fluorescence intensity per cell. In addition, a dead cell stain was performed by 
incubating the (liposome-loaded) cells with $60 \mathrm{nM}$ SYTOX ${ }^{\circledR}$ green nucleic acid stain (Molecular Probes) for 15 min at room temperature in PBS (supplemented with 5\% FBS). The viable population was identified and selected based on the SYTOX ${ }^{\circledR}$ green stain. The activation status of the $\mathrm{T}$ cells was evaluated with a phycoerythrin (PE)-labeled CD25 antibody (BD Pharmingen).

To evaluate the detachment of the liposomes from the $\mathrm{T}$ cell surface, the liposome-loaded cells were incubated with mounting concentrations of glutathione (Sigma-Aldrich) for $30 \mathrm{~min}$ at $37^{\circ} \mathrm{C}$. The glutathione dilutions were prepared in PBS (supplemented with 5\% FBS) and the $\mathrm{pH}$ was adjusted to physiological $\mathrm{pH}$. After incubation, the released liposomes were removed by washing the cells in PBS (supplemented with 5\% FBS) and the remaining DiD fluorescence per $\mathrm{CD} 8^{+} \mathrm{T}$ cell was quantified by flow cytometry. Flow cytometry data were acquired by a FACSCalibur ${ }^{\mathrm{TM}}$ (BD Pharmingen) and analyzed using BD CellQuest ${ }^{\mathrm{TM}}$ and FlowJo (Treestar Inc, Ashland, USA) software.

Characterization of detached liposomes by fluorescence single particle tracking (fSPT):

$\mathrm{CD}^{+} \mathrm{T}$ cells were first incubated with PDP-functionalized liposomes that were fluorescently labeled with DiD as described in the previous section, followed by two washing steps with PBS to remove the unbound particles. Subsequently, the cells were incubated with $2 \mathrm{mg} \mathrm{ml}^{-1}$ glutathione during $30 \mathrm{~min}$ at $37^{\circ} \mathrm{C}$. After centrifugation of the cells, the supernatant was collected and analyzed by fSPT. The latter technique enables the measurement of the size of NPs in biological fluids by recording the movement of fluorescently labeled particles. The DiD fluorophores in the liposomes were excited by swept-field laser illumination (100 mW Spectra Physics Excelsior 642 nm, CA, USA) on an epi-fluorescent microscope (Eclipse T, Nikon BeLux, Brussels, Belgium) equipped with a Plan Apo VC 100x 1.4 NA oil immersion objective lens (Nikon). The diffusion of individual liposomes was recorded in high-speed movies by a fast and sensitive CCD camera (Ixon Ultra 897, Andor Technology, CT, USA). 
The motion trajectories of single particles were obtained by in-house developed software. Subsequently, the diffusion coefficient for each trajectory was calculated and transformed in a size distribution using the Stokes-Einstein equation. Data were further refined by the maximal entropy deconvolution method, as described by our group previously [32].

\section{Visualization of T cell surface-conjugated liposomes by confocal microscopy:}

DiD-labeled liposomes were conjugated to the cell surface of $\mathrm{CD}^{+} \mathrm{T}$ cells as previously described, followed by a cell nucleus stain with $10 \mu \mathrm{g} \mathrm{ml}^{-1}$ Hoechst 33342 (Molecular Probes) and a CD8-AlexaFluor488 antibody stain (BD Pharmingen). The dyes were respectively excited by a $636 \mathrm{~nm}$ diode laser, a $408 \mathrm{~nm}$ diode laser, and a $488 \mathrm{~nm}$ argon-ion laser (all purchased from CVI Melles Griot). Images were recorded with a Plan Apo VC 60x 1.4 NA oil immersion objective lens (Nikon).

\section{T cell proliferation assay:}

$\mathrm{CD}^{+} \mathrm{T}$ cells activated during 9 days were first stained with $7.5 \mu \mathrm{M}$ CFSE (Life Technologies, Merelbeke, Belgium) and subsequently conjugated with DiD-labeled liposomes as previously described. The proliferation of the $\mathrm{T}$ cells was then measured by the dilution of the CFSE stain over the daughter cells with flow cytometry at varying time points ( $0 \mathrm{~h}, 24 \mathrm{~h}$ and $48 \mathrm{~h}$ ) after loading. The distribution of the liposomes over the daughter cells was determined by measuring the DiD fluorescence intensity per cell. During the experiment, the activated cells were incubated in cell culture medium supplemented with $30 \mathrm{U} \mathrm{ml}^{-1} \mathrm{rIL}-2$.

In vitro cytotoxic $T$ cell (CTL) assay:

EL4 and E.G7-OVA cells were stained with $5 \mu \mathrm{M}$ and $15 \mu \mathrm{M}$ CFSE stain, respectively. The OT-I CTLs were activated for 9 days with anti-CD3/CD28 Dynabeads ${ }^{\circledR}$ and incubated with PDP-functionalized liposomes at a concentration of $5 \mathrm{mg} \mathrm{ml}^{-1}$ lipids, followed by two washing steps to remove unbound particles. Subsequently, the OT-I T cells were co-cultured with EL4 and E.G7-OVA cells at two different effector-to-target ratios. To increase cell 
contact between $\mathrm{T}$ cells and target cells, the incubation was performed in a U-bottom 96-well plate (Falcon, BD Biosciences) in complete T cell culture medium. After $4 \mathrm{~h}$ at $37{ }^{\circ} \mathrm{C}$ the ratio of EL4 cells compared to E.G7-OVA cells was quantified by flow cytometry, in which the viable population was selected based on forward scatter/side scatter and both cell lines could be distinguished by their different CFSE fluorescence intensity signal.

Coupling of siRNA-loaded nanoparticles to $C D 8^{+}$T cells:

Our group has developed biodegradable dextran nanogels (NGs) via an inverse mini-emulsion photopolymerization of dextran hydroxyethyl methacrylate (dex-HEMA) in mineral oil. To incorporate cationic charges in the nanoscopic hydrogel network, cationic methacrylate monomers ([2-(methacryloyloxy)-ethyl]trimethylammonium chloride, TMAEMA, SigmaAldrich) were copolymerized with dex-HEMA [33]. Recently, experimental evidence was provided that these siRNA-loaded NGs (siNGs) can efficiently be coated with a lipid bilayer [34]. Here, the NGs were first loaded with 5 pmol AlexaFluor488-labeled siRNA (Eurogentec, Seraing, Belgium) per $\mu \mathrm{g}$ NGs. Next, the siNGs were layered with a lipid mixture composed of $50 \mathrm{wt} \%$ PE-PDP, $3 \mathrm{wt} \%$ DiD, and $47 \mathrm{wt} \%$ DOPC. Briefly, the siNGs were incubated for $10 \mathrm{~min}$ at $4^{\circ} \mathrm{C}$ with the hydrated lipid mixture, allowing electrostatic interaction, applying $10 \mathrm{mg}$ lipid per mg NGs. After incubation, the lipid coat was formed by high-energy sonication using a probe sonicator (amplitude $10 \%$, Branson Digital Sonifier ${ }^{\circledR}$, CT, USA). The lipid-coated siNGs were separated from excess lipids by centrifugation through a $7.5 \mathrm{wt} \%$ OptiPrep $^{\mathrm{TM}}$ (Sigma-Aldrich) cushion for $30 \mathrm{~min}$ at $30000 \mathrm{~g}$ (L8-70M Centrifuge with SW55 Ti rotor; Beckman Coulter, Suarlée, Belgium). The supernatant, containing empty lipid vesicles, was discarded. The resulting pellet, containing the purified lipid-coated siNGs, was resuspended in nuclease-free water. Subsequently, equal volumes of the resuspended formulation and double-concentrated PBS were mixed, in order to obtain physiological salt concentrations. Using this protocol, lipid-coated siNGs were obtained with 
a hydrodynamic diameter around $400 \mathrm{~nm}$ as analyzed using fluorescence single particle tracking (fSPT) [35].

The lipid-coated siNGs $\left(0.25 \mathrm{mg} \mathrm{ml}^{-1} \mathrm{NG}\right)$ were incubated with $3 \times 10^{5} \mathrm{CD}^{+} \mathrm{T}$ cells $(9$ daysactivated) for $45 \mathrm{~min}$ at $37^{\circ} \mathrm{C}$ in serum-free advanced RPMI. Cells were washed with PBS (supplemented with 5\% FBS). The amount of lipid-coated siNGs per cell was quantified by flow cytometry and visualized by confocal microscopy, as previously described. Flow cytometry data were acquired by a CytoFLEX (Beckman Coulter) and analyzed using FlowJo software.

\section{Quantifying siRNA release via fluorescence fluctuation spectroscopy:}

Fluorescence fluctuation spectroscopy (FFS) is a microscopy-based technique that monitors fluorescence intensity fluctuations in the excitation volume of a confocal microscope. Fluorescence fluctuations originate from the diffusion of fluorescent molecules in and out the excitation volume. To calculate the percentage free siRNA in the formulation, a fluorescence baseline of free siRNA molecules was recorded and compared with the baseline of the complexed siRNA. Upon encapsulation in NPs, the fluorescence baseline of the siRNA molecules will drop, from which the loading efficiency can be calculated as described earlier. As was shown by our group, the complexation of siRNA molecules in NPs can be determined in different media including full human serum [35]. Within this study, the siRNA release from the non-coated versus lipid-coated siNGs was measured in the presence of competing polyanions such as dextran sulfate (DEXS; 10kDa; $2.5 \mathrm{mg} \mathrm{ml}^{-1}$; Sigma-Aldrich) and human serum (obtained from a healthy donor and stored at $-20^{\circ} \mathrm{C}$ ). Equal volumes of serum or the competing polyanions in HEPES buffer were mixed with the siNGs and incubated for $10 \mathrm{~min}$ at room temperature before transferring to a glass-bottom 96 well-plate for FFS analysis (Greiner Bio-One GmbH, Frickenhausen, Germany). Measurements were performed with a Nikon C1si confocal laser scanning microscope (Nikon Benelux) equipped with a Plan Apo 
60x 1.2 NA water immersion objective lens (Nikon), using a $488 \mathrm{~nm}$ argon-ion laser (CVI Melles Griot) This setup was combined with the detection channels of a fluorescence correlation spectrometer MicroTime 200 (Picoquant GmbH, Berlin, Germany) equipped with SymPhoTime software. Fluorescence fluctuations were recorded during $1 \mathrm{~min}$.

Statistical analysis:

A two-tailed Student's t-test was performed to determine statistical differences between datasets. All statistical analyses were performed using GraphPad Prism 6 software (La Jolla, CA, USA). p-values $<0.05$ were regarded significant. Statistical significance is indicated as follows: $* * \mathrm{p}<0.01 ; * * * \mathrm{p}<0.001 ; * * * * \mathrm{p}<0.0001$ 


\section{Results}

\subsection{Liposomes for reversible attachment to cytotoxic $\mathbf{T}$ lymphocytes}

Within this study liposomes were selected as model nanoparticles (NPs) to optimize reversible coupling to cytotoxic T lymphocytes (CTLs). Varying amounts of thiol-reactive phospholipids, carrying a pyridyldithiopropionate (PDP) head group, were incorporated in the liposome bilayer, next to DOPC lipids. The PDP moiety can form a reducible disulfide bond with the thiol groups exposed at the cell surface (exofacial thiols), allowing the reversible covalent coupling of the liposomes (Figure 1A) [36]. Importantly, PDP-functionalized lipids (PE-PDP lipids) contain a negative charge that may interact with cationic regions at the plasma membrane, thereby possibly causing nonspecific binding [37]. To account for these nonspecific interactions, the cellular attachment of control liposomes, in which the PDPfunctionalized lipids were replaced by the negatively charged phosphatidylglycerol (PG) lipids, was evaluated in parallel. Both PDP and PG liposomes have a similar hydrodynamic diameter $(\sim 150 \mathrm{~nm})$ and zeta potential, of which the latter depends on the liposomal composition. For instance, when $50 \mathrm{wt} \%$ PDP or PG lipids were incorporated, a mean zeta potential value around $-65 \mathrm{mV}$ was measured. Whenever other compositions were used, their respective zeta potential values are indicated in a table additional to the experimental data. 


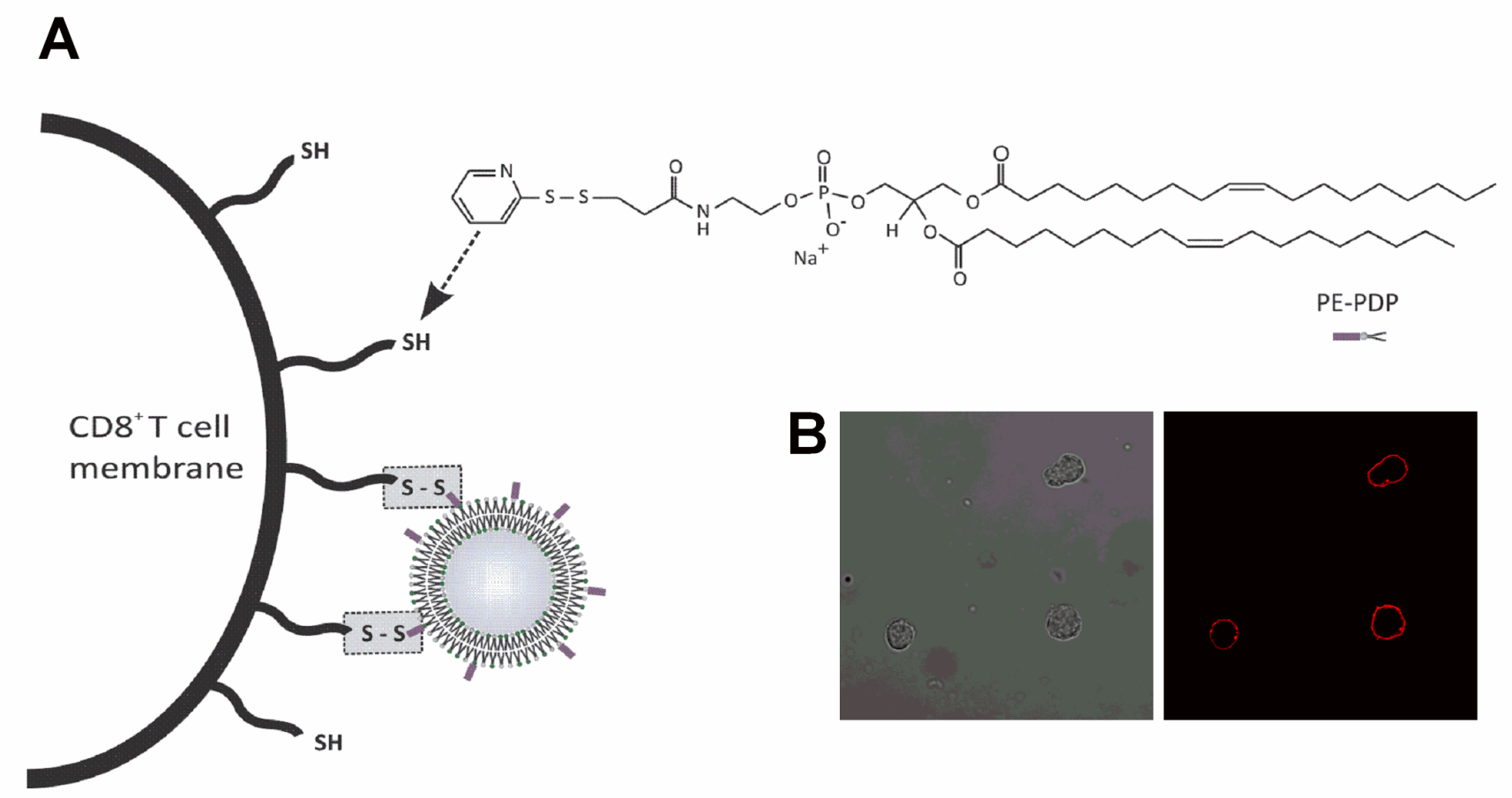

Figure 1. (A) Schematic representation of the formation of a disulfide bond between PDPfunctionalized lipids that are incorporated into the liposome bilayer and reduced exofacial thiol groups, present at the cell surface. (B) Transmission and confocal fluorescence images of non-activated murine OT-I CD8 ${ }^{+} \mathrm{T}$ cells incubated with Cy5-labeled maleimide.

\subsection{Reversible coupling of liposomes to the surface of non-activated $\mathrm{CD8}^{+} \mathrm{T}$ cells}

Murine OT-I CD8 ${ }^{+} \mathrm{T}$ cells, which are genetically engineered to express a $\mathrm{T}$ cell receptor (TCR) against ovalbumine (OVA), were selected as carriers for the cell-mediated delivery of the liposomes. To allow the formation of a disulfide bond between free thiol groups at the CTL plasma membrane and PDP liposomes, we first assessed the availability of free thiol groups at the $\mathrm{CD}^{+} \mathrm{T}$ cell surface by incubating them with Cy5-labeled maleimide [36]. The maleimide group can interact with thiol groups to form a stable thioether bond. Confocal images clearly demonstrated the presence of thiol groups that appeared to be uniformly distributed over the entire cell surface (Figure 1B). 


\subsubsection{Attachment of liposomes to the surface of non-activated $C D 8^{+} T$ cells}

Isolated $\mathrm{CD} 8^{+} \mathrm{T}$ cells from the spleen of OT-I mice were incubated with fluorescently labeled (DiD) liposomes and the amount of liposomes coupled to the cell surface was quantified by flow cytometry. We first determined the fraction of PDP lipids that needs to be incorporated into the liposomal membrane to achieve efficient binding. To this end, the cells were incubated with liposomes containing increasing amounts of PDP lipids, ranging from 10 to $50 \mathrm{wt} \%$. Cells were incubated with a $2 \mathrm{mg} \mathrm{ml}^{-1}$ lipid concentration as we determined that a higher concentration only results in a moderate increase in cellular attachment (Figure S1). To quantify nonspecific interactions, the cellular binding of PG liposomes with PG lipid wt\% also ranging from 10 to 50, was determined in parallel. It was verified that both PDP and PG liposomes have equivalent zeta potentials (Figure 2A). As displayed in Figure 2B, the nonspecific binding was independent of the liposomal composition. Strikingly, only liposomes composed of $50 \mathrm{wt} \%$ PDP-modified lipids showed specific binding to the T cells, accompanied by a more than three-fold difference in mean fluorescence intensity per cell between PG and PDP liposomes for this composition. Hence, further experiments were performed with liposomes carrying 50 wt\% PDP-functionalized or PG lipids.

The presence of fluorescently labeled liposomes at the surface of the $\mathrm{CD} 8^{+} \mathrm{T}$ cells was visualized by confocal microscopy. The images depicted in Figure 2C show localized bright fluorescent spots at the $\mathrm{T}$ cell surface, contrary to the free thiol staining with Cy5-labeled maleimide that showed a more uniform distribution (Figure 1B). Of note, from these images it is evident that the liposomes are indeed predominantly anchored to the surface of the cells and not internalized, confirming previous reports [25, 38]. 
A

Zeta potential measurements

\begin{tabular}{|c|c|c|}
\hline$w t \%$ PG or PE-PDP & $P G(m V)$ & $\mathrm{PDP}(\mathrm{mV})$ \\
\hline 10 & -21.20 & -18.27 \\
\hline 15 & -40.33 & -30.43 \\
\hline 25 & -54.23 & -48.23 \\
\hline 50 & -67.47 & -64.97 \\
\hline
\end{tabular}

C
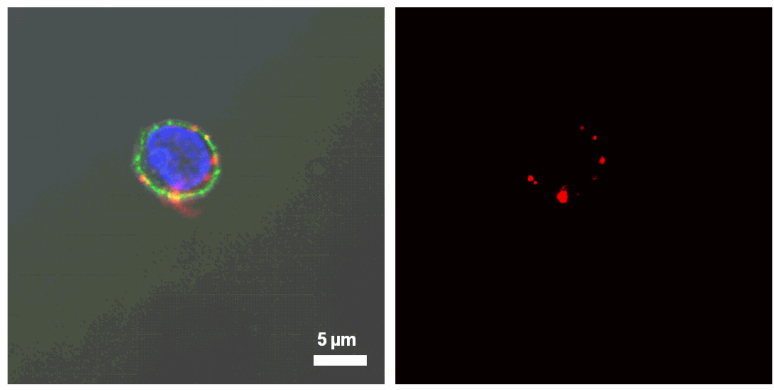

B
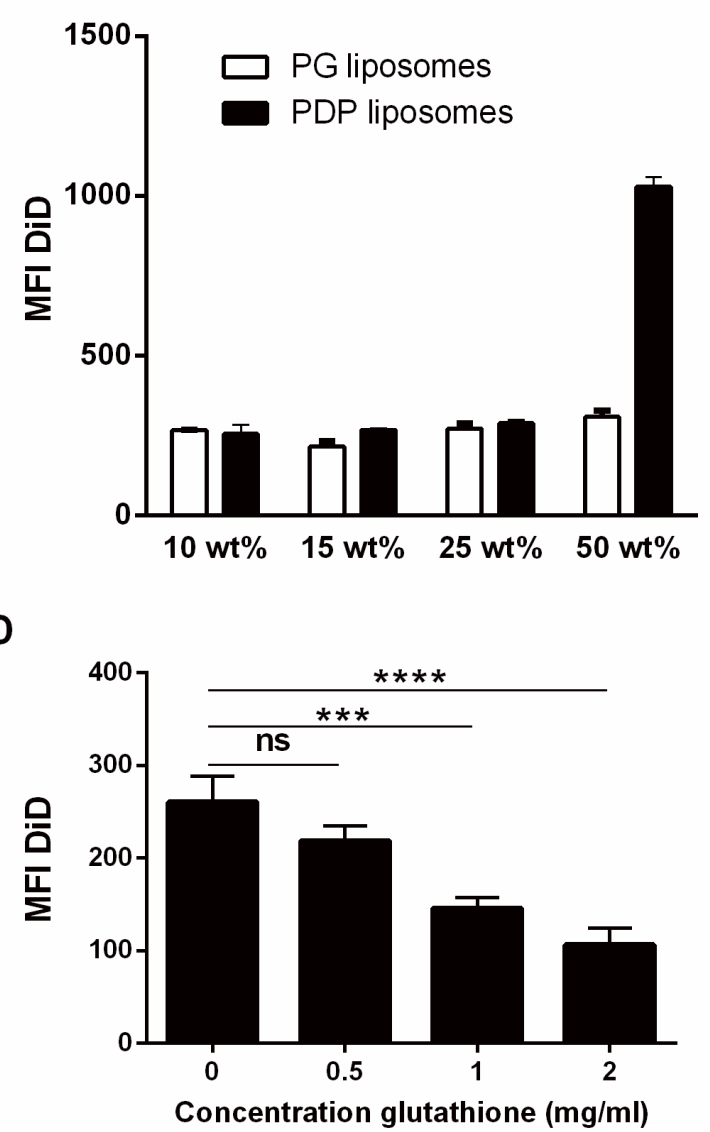

Figure 2. The reversible coupling of DiD fluorescently labeled liposomes to the surface of non-activated OT-I CD8 ${ }^{+} \mathbf{T}$ cells. (A) Zeta potential measurements of the different liposome compositions. (B) $\mathrm{CD}^{+} \mathrm{T}$ cells were incubated with PG and PDP liposomes with increasing wt\% PG and PDP lipids as indicated in the graph. Data represent DiD mean fluorescence intensity (MFI) per cell $\pm \mathrm{SD}(n=2)$. (C) Confocal overlay image (left) and red channel (right) of T cells incubated with AlexaFluor488-labeled anti-CD8 antibodies (green), Hoechst cell nucleus stain (blue), and DiD-labeled liposomes (red) (Scale bar $=5 \mu \mathrm{m}$ ). (D) Decrease in DiD MFI after incubation of the cells with increasing concentrations of glutathione. Data represent $\mathrm{MFI} \pm \mathrm{SD}(n=3 ; \mathrm{ns}=$ not significant; $* * *=\mathrm{p}<0.001 ; * * * *=\mathrm{p}<0.0001)$ 


\subsubsection{Triggered detachment of liposomes from the cell surface of non-activated $C D 8^{+} T$ cells.}

Having established the optimal liposome composition, we next sought to evaluate whether the liposomes can be detached again from the cell surface. We anticipated that incubating the liposome-loaded $\mathrm{T}$ cells with reducing agents such as glutathione can cause a thiol-disulfide exchange reaction, resulting in the release of the disulfide-bound liposomes from the $\mathrm{T}$ cell surface [39]. To explore the latter, the liposome-loaded $\mathrm{CD}^{+} \mathrm{T}$ cells were incubated with mounting concentrations of glutathione. As depicted in Figure 2D, an increase in the glutathione concentration was associated with a decrease in the amount of attached DiDlabeled PDP liposomes, indicative of their triggered release. Upon incubation with $2 \mathrm{mg} \mathrm{ml}^{-1}$ glutathione, a release of $60 \%$ of the attached particles was observed.

\subsection{Reversible coupling of liposomes to the surface of activated $\mathrm{CD8}^{+} \mathrm{T}$ cells}

Given that activated $\mathrm{T}$ cells outperform their non-activated counterparts in terms of tumor migratory capacity and cytolytic activity, we next aimed to assess the impact of $\mathrm{T}$ cell activation on the covalent coupling of liposomes. For this purpose, murine OT-I T cells were activated using anti-CD3/CD28 Dynabeads ${ }^{\circledR}$. The activation status was evaluated by the expression of the IL-2 receptor CD25, which is up-regulated after stimulation [40].

\subsubsection{Attachment of liposomes to the surface of activated $C D 8^{+} T$ cells}

Similar to the attachment of liposomes to the surface of non-activated $\mathrm{T}$ cells, the coupling of liposomes to activated $\mathrm{CD}^{+} \mathrm{T}$ cells was first quantified as a function of wt $\%$ incorporated PDP lipids. The zeta potential data from the different liposome compositions were represented in Figure 3A. In accordance with the results on non-activated $\mathrm{CD}^{+} \mathrm{T}$ cells, we again observed a significant specific binding only for the liposomes with $50 \mathrm{wt} \%$ PE-PDP lipids incorporated (Figure 3B). Thus, also for the activated $\mathrm{T}$ cells this composition was selected 
for further investigation. To evaluate the maximal coupling, the cells were incubated with increasing liposome concentrations. A sharp increase in cell binding was observed from 0.1 to $1 \mathrm{mg} \mathrm{ml}^{-1}$ lipids while a further increase up to $10 \mathrm{mg} \mathrm{ml}^{-1}$ only resulted in a moderate improvement of the coupling (Figure 3C). In analogy with non-activated T cells, liposomes bound to activated $\mathrm{T}$ cells also remain localized at the cell surface in distinct foci, as verified with confocal microscopy (Figure 3D).

A

\begin{tabular}{ccc}
\multicolumn{3}{l}{ Zeta potential measurements } \\
\hline wt\% PG or PE-PDP & PG $(\mathrm{mV})$ & PDP $(\mathrm{mV})$ \\
\hline 10 & -36.23 & -28.10 \\
25 & -62.17 & -56.43 \\
50 & -70.60 & -66.83
\end{tabular}

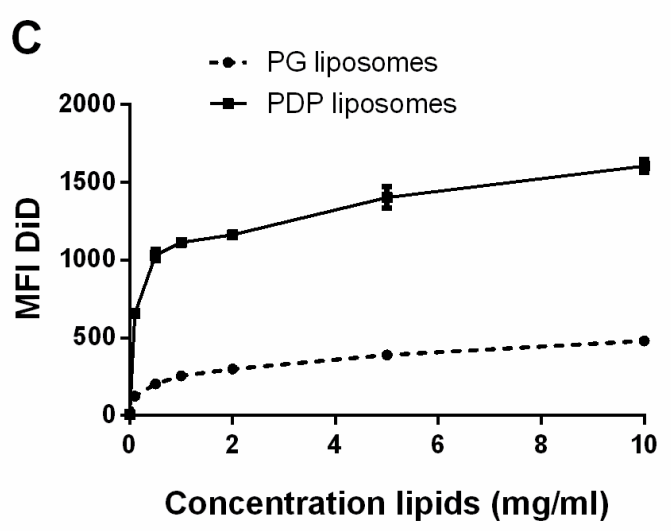

\section{B}

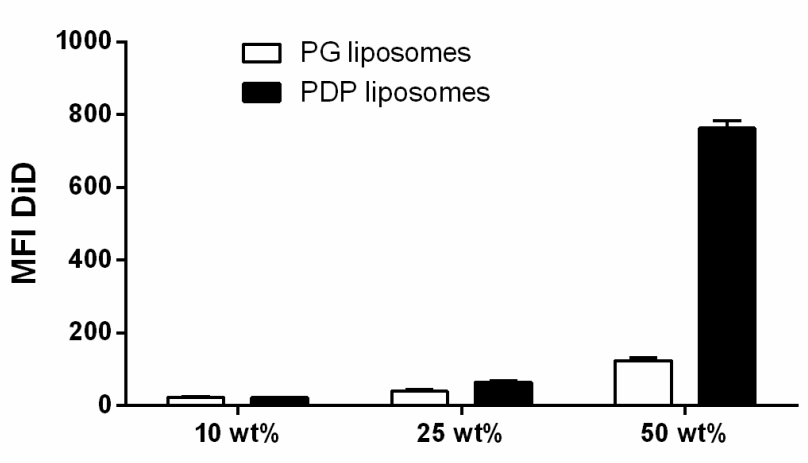

D

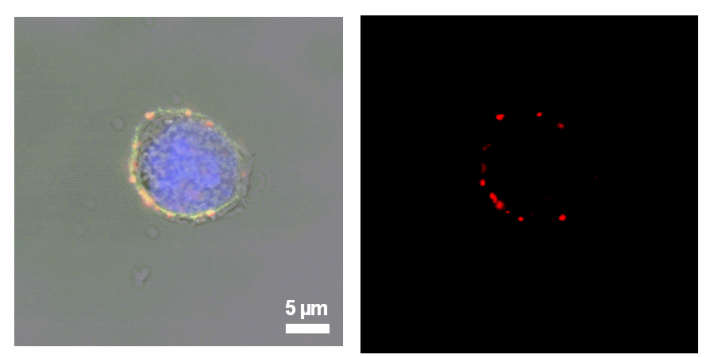

Figure 3. The coupling of DiD fluorescently labeled liposomes to the surface of activated OT-I CD8 ${ }^{+}$T cells, activated with anti-CD3/anti-CD28 Dynabeads ${ }^{\circledR}$ during 10 days. (A) Zeta potential measurements of the different liposomal compositions. (B) $\mathrm{CD}^{+} \mathrm{T}$ cells were incubated with $2 \mathrm{mg} \mathrm{ml}^{-1} \mathrm{PG}$ and PDP liposomes with increasing amounts of PG and PDP lipids as indicated. Data represent the mean fluorescence intensity (MFI) of DiD per cell \pm SD $(n=3)$. (C) Binding of DiD-labeled liposomes to 
$\mathrm{CD}^{+} \mathrm{T}$ cells as a function of lipid concentrations. Data represent DiD mean fluorescence intensity (MFI) per cell \pm SD ( $=3$ ). (D) Confocal images of $\mathrm{T}$ cells incubated with AlexaFluor488-labeled anti-CD8 antibodies (green), Hoechst cell nucleus stain (blue), and DiD-labeled liposomes (red) (Scale bar $=5 \mu \mathrm{m})$.

\subsubsection{Attachment of liposomes as a function of $T$ cell activation status}

During the activation process $\mathrm{CD}^{+} \mathrm{T}$ cells undergo phenotypic changes such as up-regulation of multiple surface markers like CD25, as represented in Figure $\mathbf{4 A}$, and a marked increase in size (Figure S2). To address whether these changes influence the attachment of particles to the cell surface, $\mathrm{CD}^{+} \mathrm{T}$ cells were activated with anti-CD3/CD28 Dynabeads ${ }^{\circledR}$ over a twoweek time period and the specific coupling of liposomes was quantified at different activation time points (Figure 4A). In accordance with the manufacturer's protocol, the cells were restimulated with new Dynabeads ${ }^{\circledR}$ on day 7 of activation.

In general, a significantly higher attachment of PDP-functionalized liposomes to activated cells was observed compared to the non-activated $\mathrm{T}$ cells. In analogy with previous experiments, PG liposomes were incubated with the $\mathrm{T}$ cells as a control for nonspecific binding. Here, a similar trend in $\mathrm{T}$ cell binding was detected, albeit with markedly lower fluorescence intensity. Furthermore, the expression of the CD25 surface marker strongly increased from day 7 to day 10 following activation, indicative of an improved $\mathrm{T}$ cell activation efficiency upon a second activation step with anti-CD3/CD28 Dynabeads ${ }^{\circledR}$ on day 7. In contrast, when exceeding 10 days of activation again a gradual decrease in CD25 expression was observed. Importantly, the efficiency of liposome coupling to the $\mathrm{T}$ cells perfectly correlates with the CD25 expression levels, also reaching optimal specific liposome attachment to the $\mathrm{T}$ cell surface at day 10 of activation. 

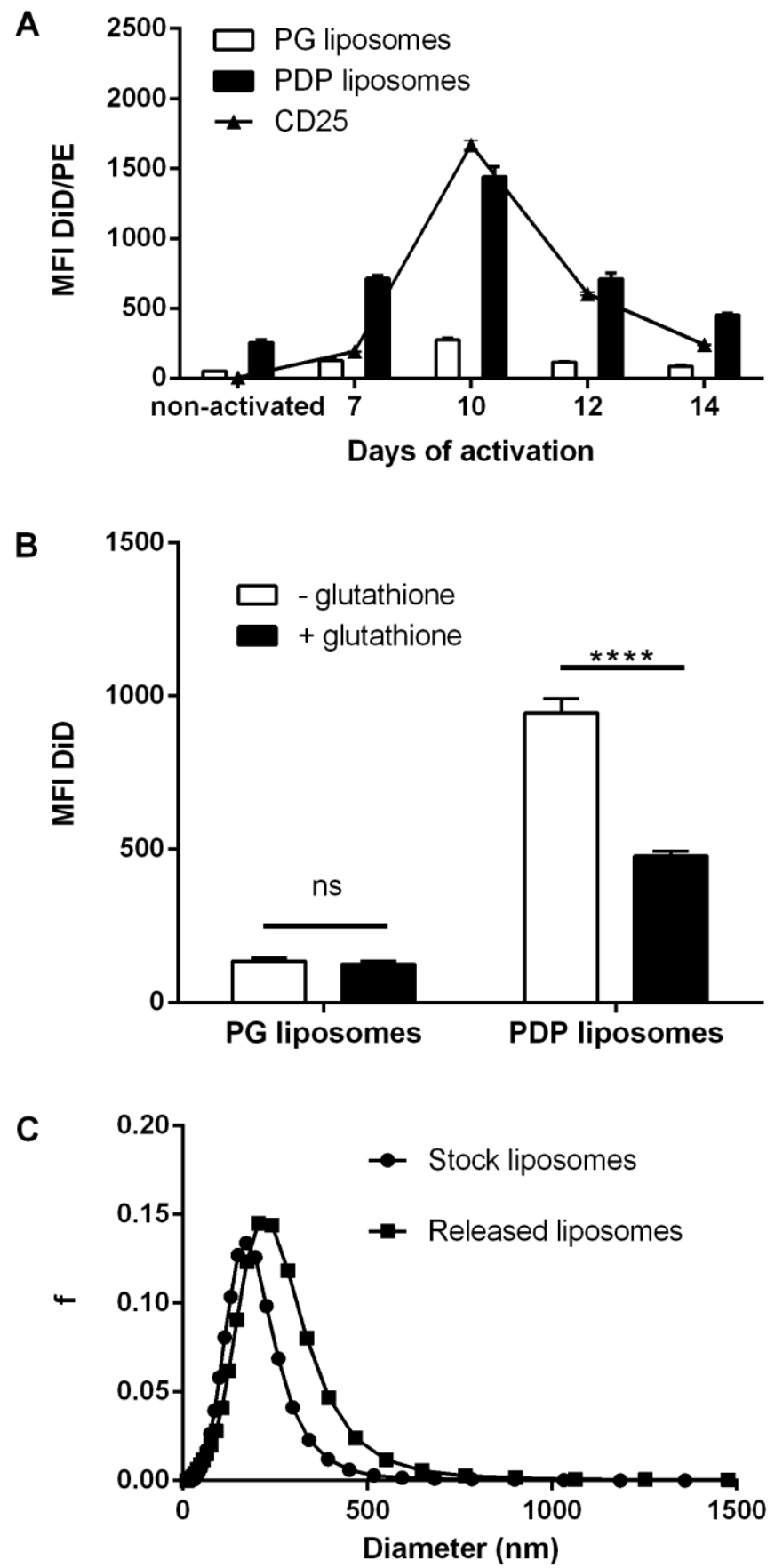

Figure 4. Reversible coupling of liposomes to the surface of OT-I $\mathrm{CD8}^{+} \mathrm{T}$ cells as a function of their activation status. (A) Attachment of DiD-labeled PG or PDP liposomes (50 wt $\%$ PG/PDP $-2 \mathrm{mg} \mathrm{ml}^{-1}$ ) to the surface of activated $\mathrm{CD}^{+} \mathrm{T}$ cells after the indicated days of activation. CD25 expression was quantified as a marker for T cell activation. Data represent the mean fluorescence intensity (MFI) per cell \pm SD from both DiD labeled liposomes (PG and PDP) and PE-labeled CD25 antibody staining $(n=4)$. (B) PG and PDP 
liposomes were attached to the surface of the cells, followed by an incubation step with or without $2 \mathrm{mg} \mathrm{ml}^{-1}$ glutathione. Data represent the DiD mean fluorescence intensity (MFI) per cell $\pm \mathrm{SD}(n=3 ; n s=$ not significant; $* * * *=p<0.0001)$. (C) Fluorescence single particle tracking (fSPT) size distribution of PDP liposomes both before $\mathrm{T}$ cell coupling and after triggered release from the $\mathrm{T}$ cell surface with glutathione.

\subsubsection{Triggered detachment of liposomes from the cell surface of activated $C D 8^{+} T$ cells}

To verify that the coupling of PDP liposomes to the surface of activated $\mathrm{T}$ cells was indeed reversible, the release of liposomes from the surface was evaluated by incubating the activated and liposome-loaded $\mathrm{CD}^{+} \mathrm{T}$ cells with glutathione. In accordance with the data obtained from non-activated $\mathrm{T}$ cells, the glutathione concentration was fixed at $2 \mathrm{mg} \mathrm{ml}^{-1}$. Glutathione was able to release $\sim 50 \%$ of the PDP liposomes from the $\mathrm{CD}^{+} \mathrm{T}$ cells surface, while the DiD fluorescence per cell for the nonspecifically bound PG liposomes remained unaffected (Figure 4B). Confocal images of cells incubated with or without glutathione are represented in Figure S3.

To determine whether the released liposomes still have the required size to allow subsequent internalization by target cells, we analyzed the size of the detached particles in the extracellular medium by fluorescence single particle tracking (fSPT). This technique is a microscopy-based method in which fluorescently labeled particles are illuminated by laser light and the Brownian motion of the particles is recorded by a fast and sensitive EMCCD camera. Based on the trajectories of single particles, calculated from the recorded movies by specialized algorithms, the diffusion coefficient and hence the hydrodynamic size of the moving particles can be determined, even in complex biological fluids [32]. A comparison was made between the liposomes prior to the $\mathrm{T}$ cell coupling and the liposomes collected after detachment from the $\mathrm{T}$ cell surface with glutathione. The average initial liposome size of 
$178 \mathrm{~nm}$, as measured by fSPT, is comparable with a diameter of $150 \mathrm{~nm}$ obtained with DLS. The liposomes that were released from the $\mathrm{T}$ cell surface in the presence of glutathione have a slightly increased average diameter $(228 \mathrm{~nm})$, which remains within an acceptable size range for subsequent endocytosis by tumor cells (Figure 4C).

\subsection{Influence of cell surface-attached liposomes on $\mathbf{T}$ cell functionalities}

\subsubsection{Proliferation of $\mathrm{CD}^{+} \mathrm{T}$ cells after coupling of liposomes}

Proliferation is one of the key cellular functions of $\mathrm{T}$ cells upon activation. We therefore sought to evaluate whether the proliferative capacity of the cells could be compromised at the highest achievable liposome-conjugation in this study. The proliferation of $\mathrm{T}$ cells was determined by staining the activated T cells with CFSE and following the subsequent dilution of this stain over the daughter cells as a function of cell division. To this end, the cells were first incubated with a high concentration of $50 \mathrm{wt} \%$ PDP liposomes $\left(20 \mathrm{mg} \mathrm{m}^{-1}\right.$ lipid concentration) for which a maximal coupling is expected (Figure 3). For the untreated T cells, a clear decrease in CFSE fluorescence intensity could be observed over time, reflecting CFSE dilution by $\mathrm{T}$ cell division. Importantly, $\mathrm{T}$ cells carrying a maximal amount of PDP liposomes on their surface also maintained a normal proliferative behavior (Figure 5A). Furthermore, the cell surface-attached liposomes were equally distributed over the daughter cells during cell division as was demonstrated by the simultaneous dilution of the DiD fluorescent signal per cell, albeit with all cells still positive for DiD after 48h (Figure 5B). 

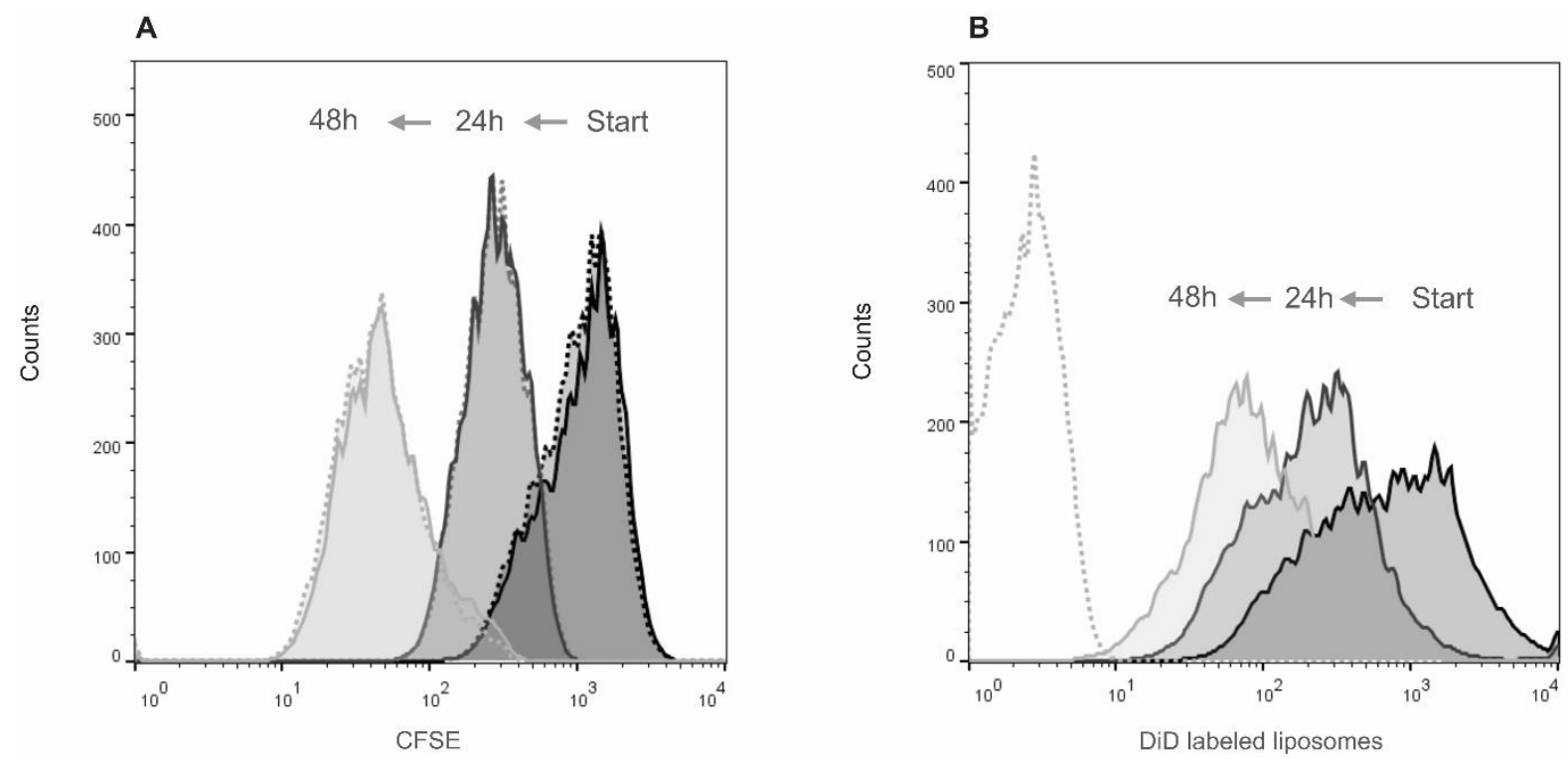

Figure 5. Proliferation of OT-I $\mathrm{CD8}^{+} \mathrm{T}$ cells after liposome coupling to the cell surface. $\mathrm{CD}^{+} \mathrm{T}$ cells were first labeled with CFSE and incubated with a high concentration of $50 \mathrm{wt} \%$ PDP liposomes labeled with DiD (20 mg ml${ }^{-1}$ lipids), followed by the incubation over $24 \mathrm{~h}$ and 48h within cell culture medium supplemented with $30 \mathrm{U} \mathrm{ml}^{-1}$ rIL-2. (A) Flow cytometry histograms representing the CFSE fluorescence intensity and (B) liposomal DiD fluorescence intensity per T cell for both liposome-loaded (solid line) and non-loaded cells (dotted line) at the start of incubation (black line), after 24h (dark gray line), and after 48h (light gray line).

\subsubsection{Cytotoxic T cell effector function after coupling of liposomes}

CTLs are designed to specifically kill target tumor cells. To evaluate whether the anchoring of liposomes to the surface of $\mathrm{CD} 8^{+} \mathrm{T}$ lymphocytes affects their cytotoxic function, OT-I T lymphocytes were used that have a TCR recognizing an ovalbumine (OVA)-derived peptide. Co-culturing of OT-I T cells with E.G7-OVA lymphoma cells that present this OVA-peptide in MHC class I, would result in TCR-mediated killing of the E.G7-OVA cells. Isogenic yet OVA negative EL4 cells were included in the co-culture experiment as a control for the specificity of this interaction. To discriminate both cell types, EL4 and E.G7-OVA cells, were 
stained with a low and high concentration of CFSE, respectively. The CFSE-labeled EL4 and E.G7-OVA cells were mixed in equal amounts followed by the addition of the OT-I T cells in an effector:target (E:T) ratio of 1:1 and 1:20 as indicated in Figure 6. A schematic of this experiment is represented in supplementary Figure S4.

At a 1:1 effector:target ratio the OT-I T cells were able to lyse the majority of the E.G7-OVA population in contrast to the EL4 cells that remained unaffected, reflecting the specificity of the CTL effector function assay. Notably, Figure 6B clearly demonstrates that the covalent attachment of liposomes to the $\mathrm{T}$ cell surface does not interfere with their cytotoxic function as both liposome-loaded and non-loaded T cells killed 72\% of the E.G7-OVA population. To exclude the possibility that this E:T ratio was too high and could therefore obscure the inhibitory effect of the conjugated liposomes, the co-culture experiment was repeated at a suboptimal E:T ratio of 1:20. Although the killing effect of the E.G7-OVA cells obtained at the $1: 20$ ratio is strongly reduced with only $6 \%$ lysis compared to $72 \%$ for the $1: 1$ ratio, again the attachment of liposomes to the $\mathrm{T}$ cell surface did not affect target cell lysis (Figure 6C). Quantitative data of this CTL assay are represented in Figure S5. 

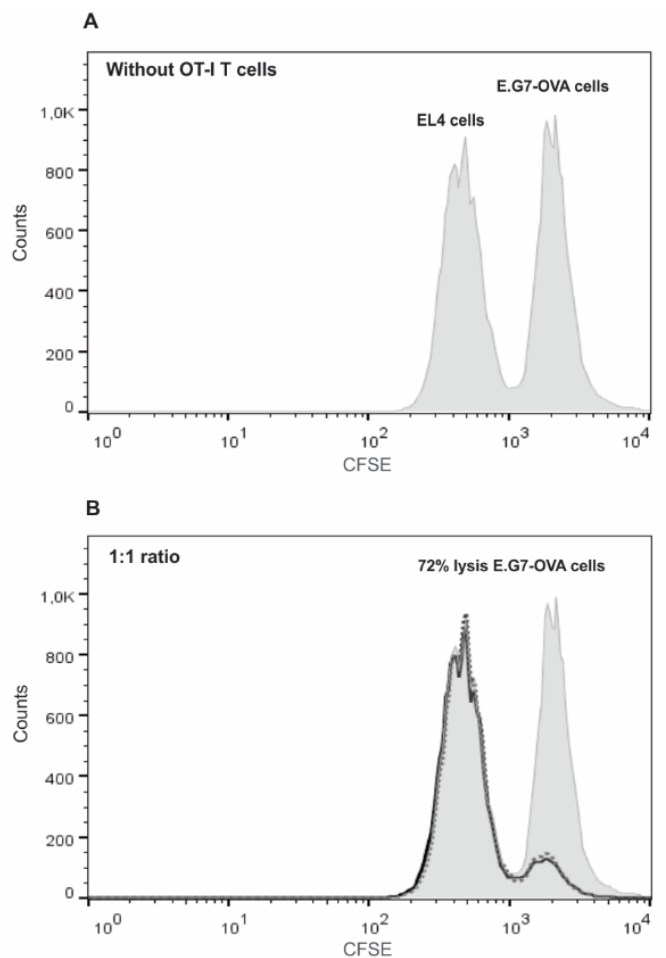

C

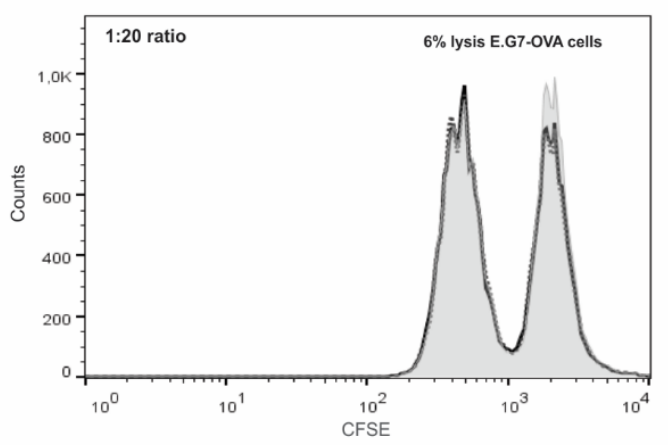

Without T cells $\quad$..... Non-loaded T cells $\quad$ - Liposome-loaded T cells

Figure 6. Co-culture of (liposome-loaded) OT-I $\mathrm{CD8}^{+} \mathrm{T}$ cells with E.G7-OVA target cells and EL4 control cells. (A) E.G7-OVA cells and EL4 cells were labeled with a high and low CFSE concentration, respectively. Both cells were mixed in equal amounts and incubated for $4 \mathrm{~h}$ at $37^{\circ} \mathrm{C}$ without $\mathrm{T}$ cells (gray fill), with non-loaded $\mathrm{T}$ cells (dotted line), and with liposome-loaded ( $5 \mathrm{mg} \mathrm{ml}^{-1}$ lipids) $\mathrm{T}$ cells (solid line). Cells were mixed in both a (B) 1:1 effector:target $(\mathrm{E}: \mathrm{T})$ ratio and a $(\mathrm{C})$ 1:20 E:T ratio. 


\subsection{Coupling of siRNA-loaded nanoparticles to $\mathrm{CD8}^{+} \mathrm{T}$ cells}

Next, a drug-loaded nanoparticle was developed for anchoring to the surface of $\mathrm{CD}^{+} \mathrm{T}$ cells, exploiting our previously optimized coupling protocol. As a therapeutic agent we selected small interfering RNA (siRNA), which needs to be delivered into the cytosol of target cells to activate gene silencing. However, as the PDP-liposomes are negatively charged they do not allow loading of siRNA based on electrostatic interaction. To this end, our research group recently developed a hybrid core-shell formulation, in which siRNA is pre-loaded in a biodegradable cationic nanogel (NG) core that is subsequently coated with a negatively charged lipid shell [34]. Here, we modified this nanocomposite formulation using PDPliposomes to construct the outer lipid shell and to enable subsequent coupling of the siRNAloaded nanogels (siNGs) to the $\mathrm{CD} 8^{+} \mathrm{T}$ cell surface.

Following incubation of this core-shell formulation with activated $\mathrm{CD} 8^{+} \mathrm{T}$ cells, we could demonstrate their coupling to the $\mathrm{T}$ cell surface. In Figure 7A, confocal images show the coupling of double-labeled PDP lipid-coated siNGs to $\mathrm{CD}^{+} \mathrm{T}$ cells, in which the greenlabeled siRNA (AlexaFluor488) perfectly co-localizes with the red-labeled (DiD) lipid coat. In addition, flow cytometry plots indicated that all $\mathrm{T}$ cells were loaded with the lipid-coated siNGs as the fluorescent signals of both labeled siRNA and lipids are closely correlated (Figure 7B). During the coating procedure of the siNGs with the highly anionic PDPliposomes a small fraction $(\sim 10 \%)$ of siRNA was released from the NG core. Importantly,

Figure 7C shows that the lipid coat offers ample protection against siRNA decomplexation in the presence of high concentrations of competing polyanions and in human serum, which 
indicates the successful deposition of a protective lipid shell around the siNG core.

A
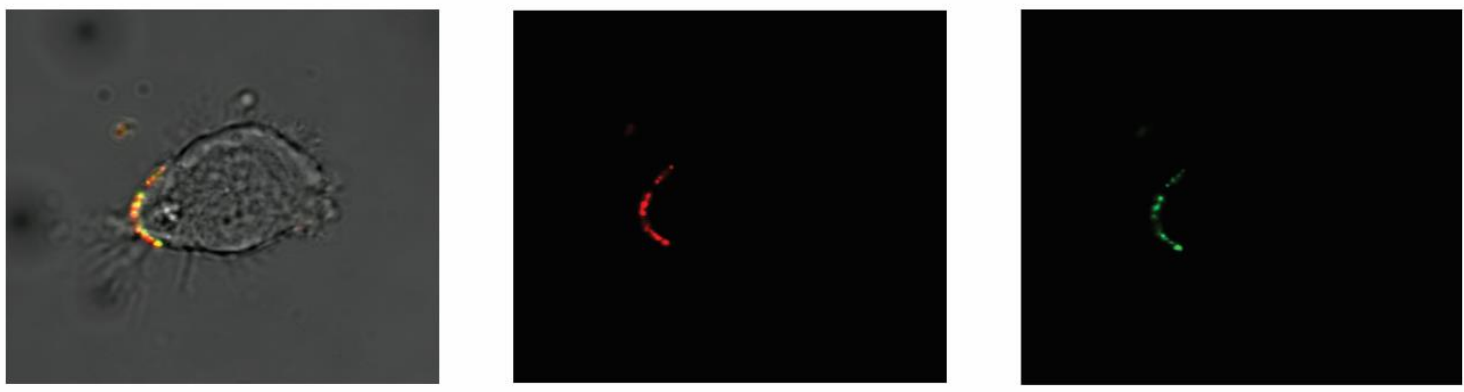

B

C
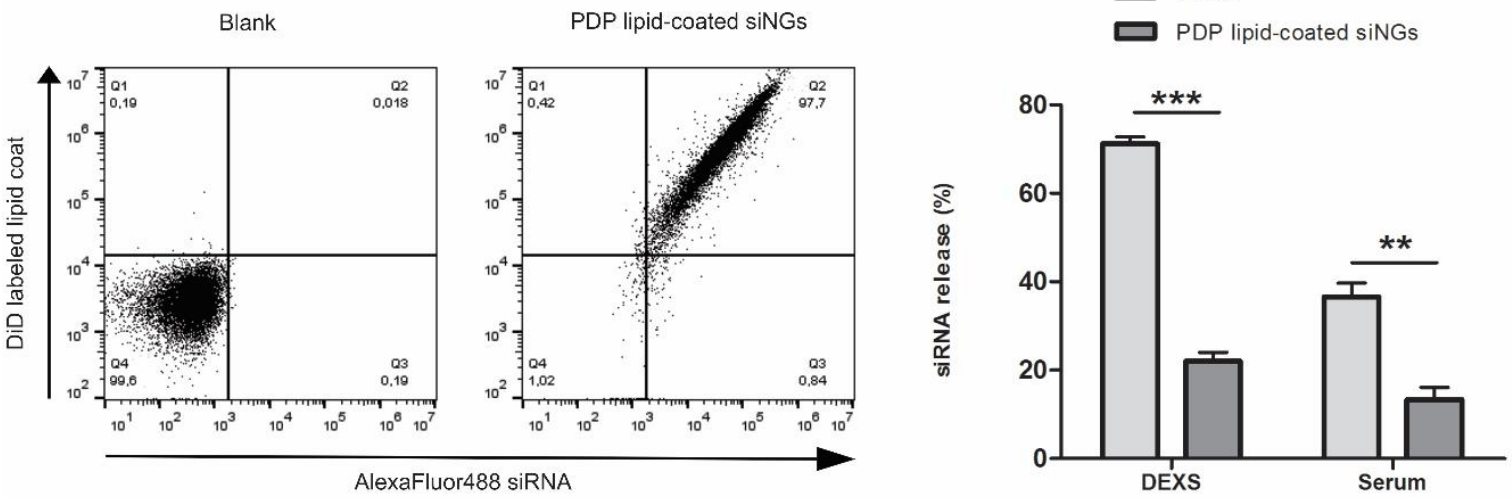

Figure 7. The coupling of siRNA-loaded nanoparticles to the surface of $\mathrm{CD8}^{+} \mathrm{T}$ cells. Nanogels (NGs) were first loaded with 5 pmol of AlexaFluor488-labeled siRNA per $\mu \mathrm{g}$ NG (siNGs), followed by coating with a lipid layer composed of $50 \mathrm{wt} \%$ PE-PDP, $3 \mathrm{wt} \%$ DiD, and $47 \mathrm{wt} \%$ DOPC. Following purification, the lipid-coated siNGs were incubated with activated $\mathrm{CD}^{+} \mathrm{T}$ cells. (A) Confocal images of lipid-coated siNGs coupled to $\mathrm{CD}^{+} \mathrm{T}$ cells via a disulfide binding. siRNA molecules were labeled with AlexaFluor488 (green) and the lipid coat was labeled with $\mathrm{DiD}$ (red). (B) Flow cytometry plots representing $\mathrm{CD}^{+} \mathrm{T}$ cells incubated with or without lipid-coated siNGs. (C) Influence of the lipid coat on the siRNA release in the presence of competing polyanions such as $2.5 \mathrm{mg} \mathrm{ml}^{-1}$ dextran sulfate (DEXS) and human serum measured by fluorescence fluctuation spectroscopy. Data represent mean \% siRNA release $\pm \mathrm{SD}(\mathrm{n}=3 ; * *=\mathrm{p}<0.01 ; * * *=\mathrm{p}<0.001)$. 


\section{Discussion}

The primary goal of this study was to investigate whether liposomes can be reversibly attached to the surface of cytotoxic T cells (CTLs). To this end, we exploited the presence of thiol groups naturally present on the surface of cells (exofacial thiols) to covalently couple liposomes that are equipped with thiol-reactive PDP groups through the formation of a disulfide bond. Our results clearly demonstrate that the surface of the $\mathrm{T}$ cells can be conjugated with high amounts of liposomes. Although the exofacial thiol groups appear to be uniformly distributed over the plasma membrane, as evaluated with Cy5-maleimide, confocal microscopy imaging revealed a more speckled distribution profile for the liposomes which is in agreement with previous observations by Irvine and colleagues [38]. It is conceivable that only a fraction of the exposed thiols at the cell surface is accessible for thiol-reactive nanoparticles (NPs) in contrast to small molecules which are less prone to steric hindrance. Another important observation is the need to incorporate a substantial fraction (50 wt $\%$ ) of thiol-reactive lipids in the liposomal formulation to achieve a significant and specific cell surface binding, both for activated and non-activated $\mathrm{T}$ cells. We hypothesize that the presence of high amounts of thiol-reactive lipids could anchor a single liposome to the $\mathrm{T}$ cell surface via multiple disulfide bonds, thereby rendering the coupled liposomes more resistant to the various washing steps and disulfide cleavage possibly occurring at the cell surface by thioredoxins and oxidoreductases that initiate thiol-disulfide exchanges [41, 42]. Our study also revealed the importance of the activation status of the $\mathrm{T}$ cells toward liposomal coupling. We could demonstrate a five-fold increase in the attachment of liposomes for T cells activated during 10 days versus non-activated T cells. Further, it was also shown that the attachment of liposomes was strongly correlated with the CD25 receptor expression, as a marker of the $\mathrm{T}$ cell activation status. Likely, the enlargement of the cells upon activation is responsible for this higher coupling efficiency, given that the concomitant increase in accessible plasma membrane surface will expose more exofacial thiols per cell. Hence, dramatic differences in 
cell surface-conjugated liposomes could be observed at different activation time points. Besides the increase in size, also the up-regulation of various surface proteins, bearing cysteine-rich extracellular domains, upon activation of the $\mathrm{T}$ cells could influence the liposome coupling efficiency. To attain a maximal drug load per $\mathrm{T}$ cell, it thus seems more appropriate to employ activated cells instead of naive $\mathrm{T}$ cells for the attachment of liposomes. Although it is recommended in adoptive $\mathrm{T}$ cell therapy to use less differentiated $\mathrm{T}$ cells, naive T cells still require ex vivo activation prior to systemic administration to be able to migrate to the tumor site. However, $\mathrm{T}$ cell proliferation upon activation results in the rapid division of the surface-conjugated liposomes over the daughter cells as shown in the proliferation assay. Considering the proliferation during the time needed for $\mathrm{T}$ cells to migrate and accumulate in the tumor $(\sim 24-72 \mathrm{~h})$ together with the lower surface liposome-loading, cell-mediated liposome delivery using naive $\mathrm{T}$ cells will likely result in a lower accumulation of drugloaded liposomes at the tumor site $[15,43]$. Importantly, the T cells loaded with the maximum amount of liposomes retain their capacity to proliferate in vitro while dividing their liposome cargo over the daughter cells. Furthermore, even when a suboptimal effector-to-target ratio was tested, a similar cytotoxic effect against target tumor cells was observed between liposome-loaded and non-loaded $\mathrm{T}$ cells. As was observed by confocal imaging, the liposomes only occupy a limited amount of the cell membrane, likely not influencing the interaction with target cells.

Within this study, the reducing agent glutathione was selected as a tumor-specific trigger for subsequent liposome detachment from the T cell surface. Indeed, glutathione levels are low in the circulation and extracellular fluids while elevated levels can be found inside cells, thus avoiding premature liposome release [44]. On the other hand, the tumor microenvironment typically shows increased thiolytic activity, originating from the release of glutathione by dead cells and the overexpression of thiolytic proteins such as thioredoxin, enabling the uncoupling of disulfide-linked NPs in the direct vicinity of tumor cells [45]. In the presence of 
glutathione, 50-60\% detachment was achieved in both activated and non-activated $\mathrm{T}$ cells. The inability to achieve complete release of the coupled liposomes is likely due to both nonspecific interactions and the requirement that multiple disulfide bonds need to be broken up simultaneously. As represented in Figure S4, the confocal images show that the partial detachment is not due to internalization of the particles, as it can be observed that the refractory particles are still located at the surface of the $\mathrm{T}$ cells. In addition, previous reports on the internalization of particles in T cells agree that the endocytic uptake of NPs in this cell type is rather exceptional. Nevertheless, we could show that the liposomes do not tend to aggregate upon release from the cell surface as only a minor increase in the liposome diameter was observed compared to the original liposomes. The latter is of key importance for the subsequent internalization of the released particles in the target tumor cells.

In general, the use of cells as carriers was inspired by the observation that certain pathogens can evade the immune system by attaching themselves to the surface of red blood cells [4648]. These observations paved the way for NP cell-mediated delivery, in which the carriers might prevent the clearance of the particles upon intravenous injection and enhance the accumulation of NPs in inaccessible regions [49-51]. Different coupling strategies have been assessed such as passive adsorption and ligand-receptor interactions, however, the covalent linkage of particles to reactive groups that are present at the cellular surface has proven most promising in terms of coupling stability $[13,52]$.

To our knowledge, this is the first study that demonstrates the reversible coupling of NPs to CTLs. This reversible strategy is of interest to improve the intratumoral delivery of both low molecular weight chemotherapeutic drugs but is of particular interest for membraneimpermeable macromolecular therapeutics, like small interfering RNA (siRNA). While the nanocarriers should prevent siRNA degradation in the systemic circulation and fast renal clearance, the T cell-mediated delivery might actively enhance its accumulation in the tumor site. Triggered detachment of the nanomedicines from the carrier cell surface should enable 
their subsequent internalization by target cells in the tumor and intracellular delivery of the therapeutic payload. In light of this concept, we developed a lipid-polymer nanocomposite that allows high siRNA loading in the polymer core and is coated with a PDP-modified lipid shell. The latter improves both NP stability and at the same time enables the functionalization of the NP surface with a PDP linker lipid to allow reducible binding to $\mathrm{CD} 8^{+} \mathrm{T}$ cells. Genetic interference using siRNAs to target genes involved in cancer cell proliferation, survival, angiogenesis, and metastasis has been widely investigated $[53,54]$. In the context of cancer immunotherapy, key regulators of the immunosuppressive pathways in immune cells of the tumor microenvironment can also be envisioned. Moreover, applying siRNA as a therapeutic agent to induce sequence-specific silencing of disease-related target genes can avoid off-target toxicity to healthy cells. The latter is also of particular importance to avoid side effects of the released drug onto the CTL carrier. Although the T-cell mediated NP delivery concept can be expanded to lipid-based NPs loaded with chemotherapeutics, within the latter approach it is imperative to also consider the possible toxic effects of the chemotherapeutic agent onto the carrier cells itself.

Although the injection of tumor-specific $\mathrm{T}$ cells as a therapy already showed impressive clinical outcomes, the limited number of patients that can be cured with this therapy is often related to the immunosuppressive role of the tumor microenvironment, the intra-tumor heterogeneity, and loss of antigens to which the adoptive $\mathrm{T}$ cell therapy was engineered [55, 56].

These factors jointly underscore the need to investigate combinatorial anti-cancer strategies leading to synergistic effects as was suggested here via the enhancement of the efficacy of the T cell therapy by the concurrent delivery of siRNA-loaded NPs, acting against adoptive T cell therapy-refractory tumor cells and/or immunosuppressive cells. Future research will be focused on the in vivo evaluation of this novel concept in validated models of adoptive $\mathrm{T}$ cell therapy. 


\section{Conclusion}

A novel technique was developed to reversibly attach lipid-based NPs to the surface of CTLs. This study revealed the importance of both the lipid composition and the cell activation status on the loading efficiency of the $\mathrm{CD} 8^{+} \mathrm{T}$ cells. Furthermore, it was shown that the presence of NPs on the cell surface does not affect the in vitro evaluated cellular functions such as proliferation and cytolytic activity. Cell-mediated delivery of NPs to tumor tissues is promising in terms of overcoming barriers that intravenously injected free NPs encounter on their way to the tumor tissue. Additionally, a reversible coupling strategy is of importance to allow subsequent internalization of the released NPs by tumor target cells, especially for the delivery of membrane-impermeable macromolecular therapeutics that require cytosolic delivery into tumor cells to be functional. To that end, we demonstrated the triggered release of disulfide-coupled liposomes from the $\mathrm{T}$ cell surface via glutathione, mimicking the thiolytic tumor microenvironment. Exploiting this optimized coupling strategy, we demonstrated the anchoring of siRNA-loaded lipid-coated nanogels to the surface of activated $\mathrm{CD}^{+} \mathrm{T}$ cells.

\section{Acknowledgements}

$\mathrm{KR}, \mathrm{HD}$, and $\mathrm{KB}$ are postdoctoral fellows of the Research Foundation-Flanders, Belgium (FWO-Vlaanderen). LW is a doctoral fellow of the Institute for the Promotion of Innovation through Science and Technology in Flanders, Belgium (IWT-Vlaanderen). LDB is a postdoctoral fellow of the Special Research Fund of Ghent University. FWO is acknowledged for their financial support (Krediet aan Navorsers). The authors would like to thank George Dakwar for kindly providing serum samples. 
[1] N. Bertrand, J. Wu, X. Xu, N. Kamaly, O.C. Farokhzad, Cancer nanotechnology: the impact of passive and active targeting in the era of modern cancer biology, Adv. Drug Delivery Rev., 66 (2014) 2-25.

[2] D. Peer, J.M. Karp, S. Hong, O.C. Farokhzad, R. Margalit, R. Langer, Nanocarriers as an emerging platform for cancer therapy, Nat. Nanotechnol., 2 (2007) 751-760.

[3] S. Mitragotri, J. Lahann, Materials for drug delivery: innovative solutions to address complex biological hurdles, Adv. Mater., 24 (2012) 3717-3723.

[4] N. Kamaly, Z. Xiao, P.M. Valencia, A.F. Radovic-Moreno, O.C. Farokhzad, Targeted polymeric therapeutic nanoparticles: design, development and clinical translation, Chem. Soc. Rev., 41 (2012) 2971-3010.

[5] V. Sanna, N. Pala, M. Sechi, Targeted therapy using nanotechnology: focus on cancer, Int. J. Nanomed., 9 (2014) 467-483.

[6] A. Chrastina, K.A. Massey, J.E. Schnitzer, Overcoming in vivo barriers to targeted nanodelivery, Wiley Interdiscip. Rev.: Nanomed. Nanobiotechnol., 3 (2011) 421-437.

[7] S. Barua, S. Mitragotri, Challenges associated with Penetration of Nanoparticles across Cell and Tissue Barriers: A Review of Current Status and Future Prospects, Nano Today, 9 (2014) 223-243.

[8] H. Maeda, H. Nakamura, J. Fang, The EPR effect for macromolecular drug delivery to solid tumors: Improvement of tumor uptake, lowering of systemic toxicity, and distinct tumor imaging in vivo, Adv. Drug Delivery Rev., 65 (2013) 71-79.

[9] U. Prabhakar, H. Maeda, R.K. Jain, E.M. Sevick-Muraca, W. Zamboni, O.C. Farokhzad, S.T. Barry, A. Gabizon, P. Grodzinski, D.C. Blakey, Challenges and key considerations of the enhanced permeability and retention effect for nanomedicine drug delivery in oncology, Cancer Res., 73 (2013) 2412-2417.

[10] D.W. Bartlett, H. Su, I.J. Hildebrandt, W.A. Weber, M.E. Davis, Impact of tumorspecific targeting on the biodistribution and efficacy of siRNA nanoparticles measured by multimodality in vivo imaging, Proc. Natl. Acad. Sci. U. S. A., 104 (2007) 15549-15554. [11] D.B. Kirpotin, D.C. Drummond, Y. Shao, M.R. Shalaby, K. Hong, U.B. Nielsen, J.D. Marks, C.C. Benz, J.W. Park, Antibody targeting of long-circulating lipidic nanoparticles does not increase tumor localization but does increase internalization in animal models, Cancer Res., 66 (2006) 6732-6740.

[12] C.H. Choi, C.A. Alabi, P. Webster, M.E. Davis, Mechanism of active targeting in solid tumors with transferrin-containing gold nanoparticles, Proc. Natl. Acad. Sci. U. S. A., 107 (2010) 1235-1240.

[13] M.T. Stephan, D.J. Irvine, Enhancing Cell therapies from the Outside In: Cell Surface Engineering Using Synthetic Nanomaterials, Nano Today, 6 (2011) 309-325.

[14] J.C. Roth, D.T. Curiel, L. Pereboeva, Cell vehicle targeting strategies, Gene Ther., 15 (2008) 716-729.

[15] A. Boissonnas, L. Fetler, I.S. Zeelenberg, S. Hugues, S. Amigorena, In vivo imaging of cytotoxic T cell infiltration and elimination of a solid tumor, J. Exp. Med., 204 (2007) 345356.

[16] J.M. Brown, W.R. Wilson, Exploiting tumour hypoxia in cancer treatment, Nat. Rev. Cancer, 4 (2004) 437-447.

[17] J.L. Markman, A. Rekechenetskiy, E. Holler, J.Y. Ljubimova, Nanomedicine therapeutic approaches to overcome cancer drug resistance, Adv. Drug Delivery Rev., 65 (2013) 18661879.

[18] C. Murdoch, A. Giannoudis, C.E. Lewis, Mechanisms regulating the recruitment of macrophages into hypoxic areas of tumors and other ischemic tissues, Blood, 104 (2004) 2224-2234. 
[19] M.R. Choi, K.J. Stanton-Maxey, J.K. Stanley, C.S. Levin, R. Bardhan, D. Akin, S. Badve, J. Sturgis, J.P. Robinson, R. Bashir, N.J. Halas, S.E. Clare, A cellular Trojan Horse for delivery of therapeutic nanoparticles into tumors, Nano Lett., 7 (2007) 3759-3765.

[20] A.C. Anselmo, J.B. Gilbert, S. Kumar, V. Gupta, R.E. Cohen, M.F. Rubner, S.

Mitragotri, Monocyte-mediated delivery of polymeric backpacks to inflamed tissues: a generalized strategy to deliver drugs to treat inflammation, J. Control. Release, 199 (2015) 2936.

[21] S.A. Rosenberg, M.E. Dudley, Adoptive cell therapy for the treatment of patients with metastatic melanoma, Curr. Opin. Immunol., 21 (2009) 233-240.

[22] S.A. Rosenberg, J.C. Yang, R.M. Sherry, U.S. Kammula, M.S. Hughes, G.Q. Phan, D.E. Citrin, N.P. Restifo, P.F. Robbins, J.R. Wunderlich, K.E. Morton, C.M. Laurencot, S.M.

Steinberg, D.E. White, M.E. Dudley, Durable complete responses in heavily pretreated patients with metastatic melanoma using T-cell transfer immunotherapy, Clin. Cancer. Res., 17 (2011) 4550-4557.

[23] L. Wayteck, K. Breckpot, J. Demeester, S.C. De Smedt, K. Raemdonck, A personalized view on cancer immunotherapy, Cancer Lett., 352 (2014) 113-125.

[24] D.S. Chen, I. Mellman, Oncology meets immunology: the cancer-immunity cycle, Immunity, 39 (2013) 1-10.

[25] M.T. Stephan, J.J. Moon, S.H. Um, A. Bershteyn, D.J. Irvine, Therapeutic Cell Engineering Using Surface-Conjugated Synthetic Nanoparticles, J. Immunother., 33 (2010) 866-866.

[26] C. Cole, J. Qiao, T. Kottke, R.M. Diaz, A. Ahmed, L. Sanchez-Perez, G. Brunn, J. Thompson, J. Chester, R.G. Vile, Tumor-targeted, systemic delivery of therapeutic viral vectors using hitchhiking on antigen-specific T cells, Nat. Med., 11 (2005) 1073-1081. [27] B. Huang, W.D. Abraham, Y. Zheng, S.C. Bustamante Lopez, S.S. Luo, D.J. Irvine, Active targeting of chemotherapy to disseminated tumors using nanoparticle-carrying $\mathrm{T}$ cells, Sci. Transl. Med., 7 (2015) 291 ra294.

[28] T.M. Allen, P.R. Cullis, Liposomal drug delivery systems: from concept to clinical applications, Adv. Drug Delivery Rev., 65 (2013) 36-48.

[29] A. Kunert, T. Straetemans, C. Govers, C. Lamers, R. Mathijssen, S. Sleijfer, R. Debets, TCR-Engineered T Cells Meet New Challenges to Treat Solid Tumors: Choice of Antigen, T Cell Fitness, and Sensitization of Tumor Milieu, Front. Immunol., 4 (2013) 363.

[30] C.A. Klebanoff, L. Gattinoni, N.P. Restifo, Sorting through subsets: which T-cell populations mediate highly effective adoptive immunotherapy?, J. Immunother., 35 (2012) 651-660.

[31] S. Snauwaert, G. Verstichel, S. Bonte, G. Goetgeluk, S. Vanhee, Y. Van Caeneghem, K. De Mulder, C. Heirman, H. Stauss, M.H. Heemskerk, T. Taghon, G. Leclercq, J. Plum, A.W. Langerak, K. Thielemans, T. Kerre, B. Vandekerckhove, In vitro generation of mature, naive antigen-specific CD8(+) T cells with a single T-cell receptor by agonist selection, Leukemia, 28 (2014) 830-841.

[32] K. Braeckmans, K. Buyens, W. Bouquet, C. Vervaet, P. Joye, F. De Vos, L. Plawinski, L. Doeuvre, E. Angles-Cano, N.N. Sanders, J. Demeester, S.C. De Smedt, Sizing nanomatter in biological fluids by fluorescence single particle tracking, Nano Lett., 10 (2010) 4435-4442. [33] K. Raemdonck, B. Naeye, K. Buyens, R.E. Vandenbroucke, A. Hogset, J. Demeester, S.C. De Smedt, Biodegradable Dextran Nanogels for RNA Interference: Focusing on Endosomal Escape and Intracellular siRNA Delivery, Adv. Funct. Mater., 19 (2009) 14061415.

[34] L. De Backer, K. Braeckmans, M.C. Stuart, J. Demeester, S.C. De Smedt, K. Raemdonck, Bio-inspired pulmonary surfactant-modified nanogels: A promising siRNA delivery system, J. Control. Release, 206 (2015) 177-186. 
[35] K. Buyens, B. Lucas, K. Raemdonck, K. Braeckmans, J. Vercammen, J. Hendrix, Y. Engelborghs, S.C. De Smedt, N.N. Sanders, A fast and sensitive method for measuring the integrity of siRNA-carrier complexes in full human serum, J. Control. Release, 126 (2008) 67-76.

[36] B. Sahaf, K. Heydari, L.A. Herzenberg, L.A. Herzenberg, Lymphocyte surface thiol levels, Proc. Natl. Acad. Sci. U. S. A., 100 (2003) 4001-4005.

[37] A. Verma, F. Stellacci, Effect of surface properties on nanoparticle-cell interactions, Small, 6 (2010) 12-21.

[38] M.T. Stephan, S.B. Stephan, P. Bak, J. Chen, D.J. Irvine, Synapse-directed delivery of immunomodulators using T-cell-conjugated nanoparticles, Biomaterials, 33 (2012) 57765787.

[39] H.F. Gilbert, Molecular and cellular aspects of thiol-disulfide exchange, Adv. Enzymol. Relat. Areas Mol. Biol., 63 (1990) 69-172.

[40] M. Shipkova, E. Wieland, Surface markers of lymphocyte activation and markers of cell proliferation, Clin. Chim. Acta, 413 (2012) 1338-1349.

[41] A.G. Torres, M.J. Gait, Exploiting cell surface thiols to enhance cellular uptake, Trends Biotechnol., 30 (2012) 185-190.

[42] P.J. Hogg, Disulfide bonds as switches for protein function, Trends Biochem. Sci., 28

(2003) 210-214.

[43] L.C. Kennedy, A.S. Bear, J.K. Young, N.A. Lewinski, J. Kim, A.E. Foster, R.A. Drezek, T cells enhance gold nanoparticle delivery to tumors in vivo, Nanoscale research letters, 6 (2011) 283.

[44] F. Meng, W.E. Hennink, Z. Zhong, Reduction-sensitive polymers and bioconjugates for biomedical applications, Biomaterials, 30 (2009) 2180-2198.

[45] T. Kaasgaard, T.L. Andresen, Liposomal cancer therapy: exploiting tumor characteristics, Expert opin. Drug Delivery, 7 (2010) 225-243.

[46] E. Chambers, S. Mitragotri, Long circulating nanoparticles via adhesion on red blood cells: mechanism and extended circulation, Exp. Biol. Med. (Maywood), 232 (2007) 958-966. [47] M. Hamidi, A. Zarrin, M. Foroozesh, S. Mohammadi-Samani, Applications of carrier erythrocytes in delivery of biopharmaceuticals, J. Control. Release, 118 (2007) 145-160.

[48] L. Rossi, S. Serafini, F. Pierige, A. Antonelli, A. Cerasi, A. Fraternale, L. Chiarantini, M. Magnani, Erythrocyte-based drug delivery, Expert opin. Drug Delivery, 2 (2005) 311-322. [49] N. Doshi, A.J. Swiston, J.B. Gilbert, M.L. Alcaraz, R.E. Cohen, M.F. Rubner, S. Mitragotri, Cell-based drug delivery devices using phagocytosis-resistant backpacks, Adv. Mater., 23 (2011) H105-109.

[50] M.R. Choi, R. Bardhan, K.J. Stanton-Maxey, S. Badve, H. Nakshatri, K.M. Stantz, N. Cao, N.J. Halas, S.E. Clare, Delivery of nanoparticles to brain metastases of breast cancer using a cellular Trojan horse, Cancer Nanotechnol., 3 (2012) 47-54.

[51] H. Cheng, C.J. Kastrup, R. Ramanathan, D.J. Siegwart, M. Ma, S.R. Bogatyrev, Q. Xu, K.A. Whitehead, R. Langer, D.G. Anderson, Nanoparticulate cellular patches for cellmediated tumoritropic delivery, ACS nano, 4 (2010) 625-631.

[52] A.C. Anselmo, S. Mitragotri, Cell-mediated delivery of nanoparticles: taking advantage of circulatory cells to target nanoparticles, J. Control. Release, 190 (2014) 531-541.

[53] E. Miele, G.P. Spinelli, E. Miele, E. Di Fabrizio, E. Ferretti, S. Tomao, A. Gulino, Nanoparticle-based delivery of small interfering RNA: challenges for cancer therapy, Int. J. Nanomed., 7 (2012) 3637-3657.

[54] J. Tabernero, G.I. Shapiro, P.M. LoRusso, A. Cervantes, G.K. Schwartz, G.J. Weiss, L. Paz-Ares, D.C. Cho, J.R. Infante, M. Alsina, M.M. Gounder, R. Falzone, J. Harrop, A.C. White, I. Toudjarska, D. Bumcrot, R.E. Meyers, G. Hinkle, N. Svrzikapa, R.M. Hutabarat, V.A. Clausen, J. Cehelsky, S.V. Nochur, C. Gamba-Vitalo, A.K. Vaishnaw, D.W. Sah, J.A. 
Gollob, H.A. Burris, 3rd, First-in-humans trial of an RNA interference therapeutic targeting VEGF and KSP in cancer patients with liver involvement, Cancer Discov., 3 (2013) 406-417. [55] G.T. Motz, G. Coukos, Deciphering and reversing tumor immune suppression, Immunity, 39 (2013) 61-73.

[56] S.M. Jensen, C.G. Twitty, L.D. Maston, P.A. Antony, M. Lim, H.M. Hu, U. Petrausch, N.P. Restifo, B.A. Fox, Increased frequency of suppressive regulatory T cells and T cellmediated antigen loss results in murine melanoma recurrence, J. Immunol., 189 (2012) 767 776. 
Supporting Information

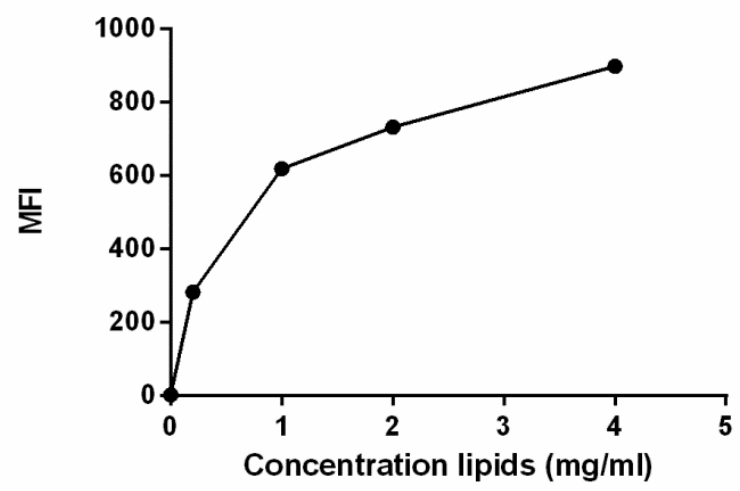

Figure S1. Binding of DiD-labeled liposomes with 50 wt\% PDP lipids to non-activated $\mathrm{CD8}^{+} \mathbf{T}$ cells as a function of total lipid concentrations. $\mathrm{CD}^{+} \mathrm{T}$ cells were incubated with increasing amounts of liposomes, composed of $50 \mathrm{wt} \%$ PE-PDP, $3 \mathrm{wt} \% \mathrm{DiD}$ and $47 \mathrm{wt} \%$ DOPC lipids. Data represent DiD mean fluorescence intensity (MFI) per cell \pm SD $(n=2)$. 

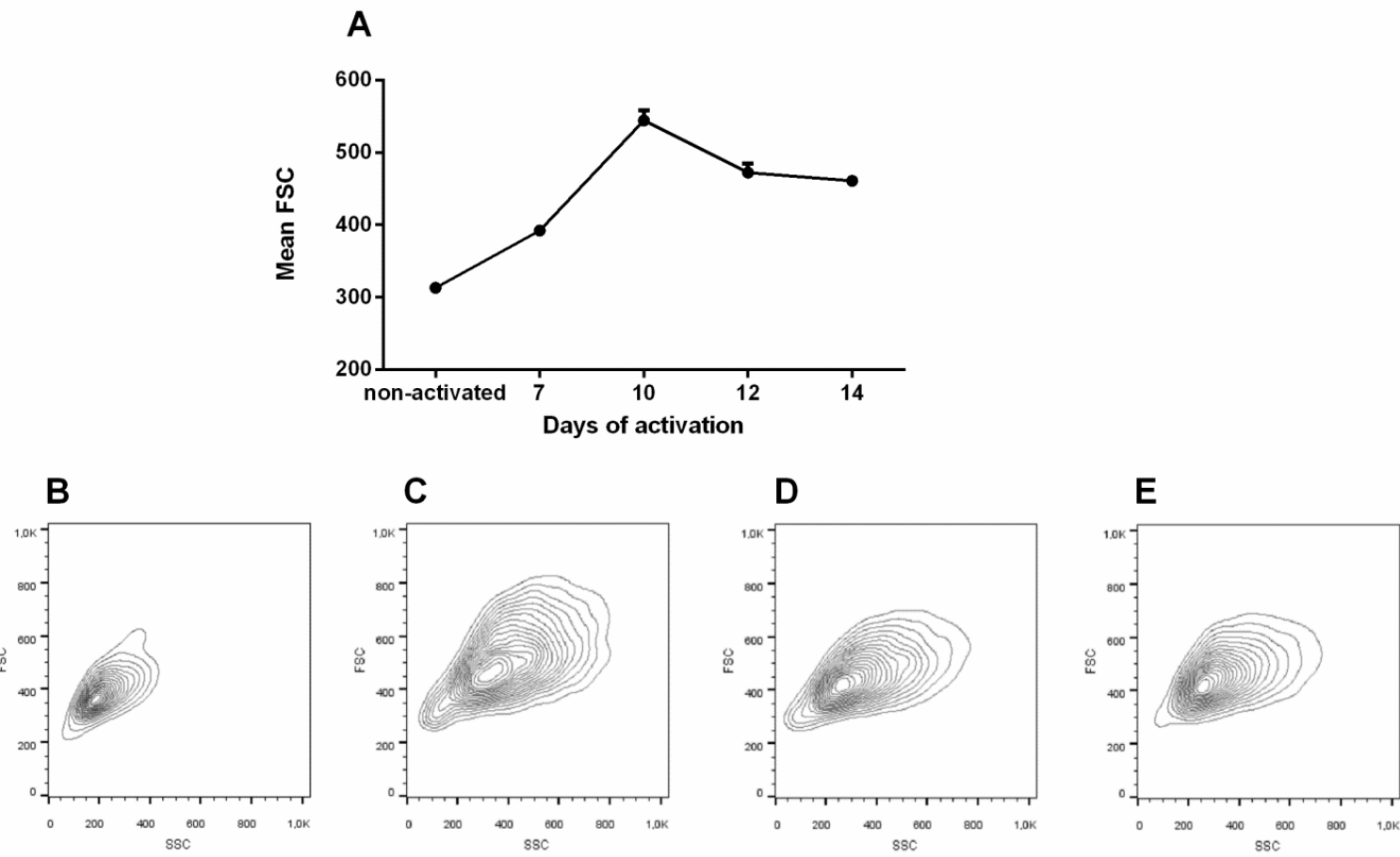

Figure S2. Size of $\mathrm{CD8}^{+} \mathbf{T}$ cells in function of activation time. (A) Mean forward scatter (FSC) \pm SD of activated $\mathrm{CD}^{+} \mathrm{T}$ cells as a function of activation time ( $n=1$ for non-activated cells and $n=3$ for activated cells). FSC and SSC plots of cells activated during (B) 7, (C) 10, (D) 12, and (E) 14 days. Data represent viable cells that were selected based on a SYTOX ${ }^{\circledR}$ green dead cell stain. 

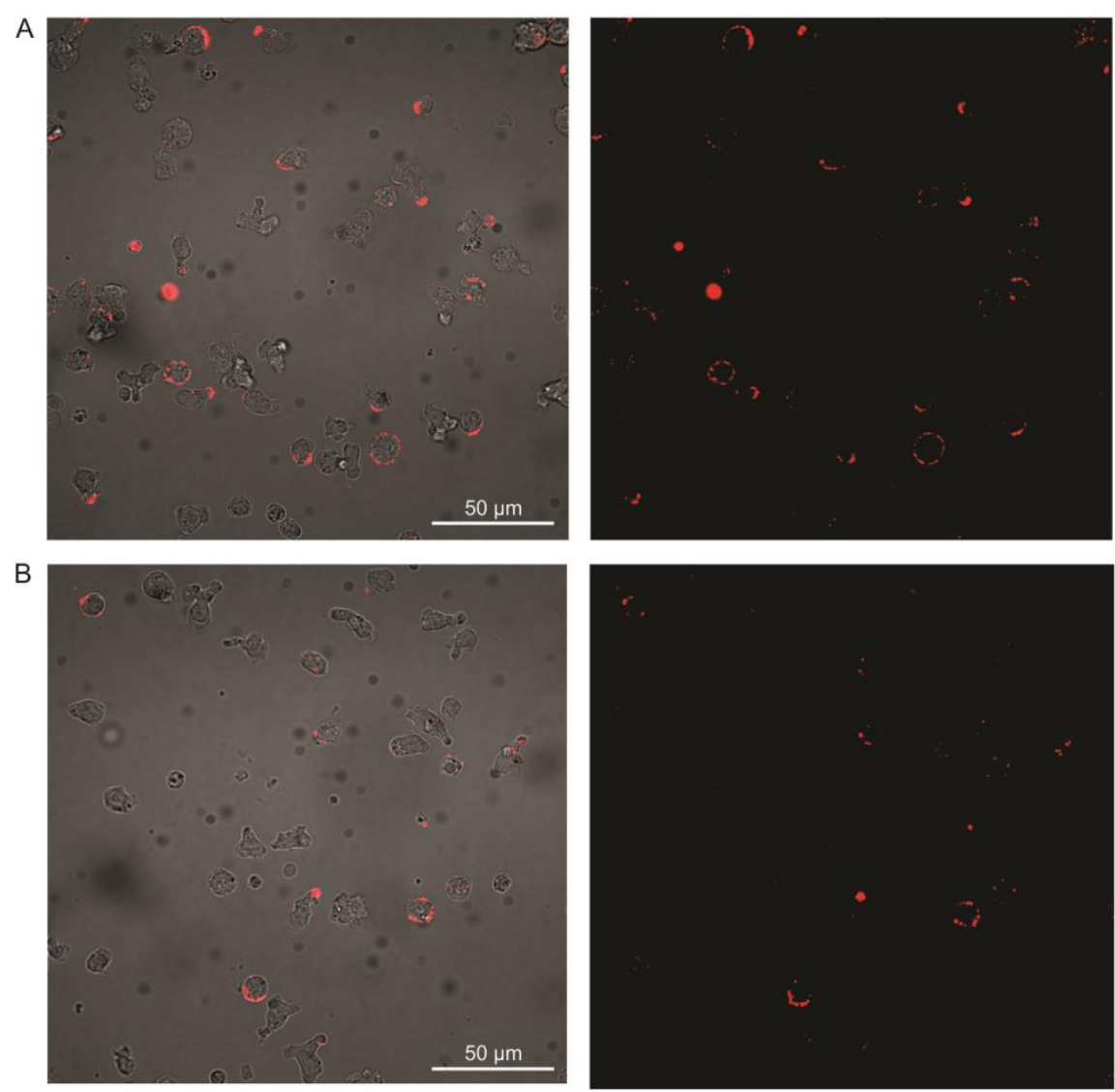

Figure S3. Confocal images of liposomes attached to $\mathrm{CD8}^{+} \mathrm{T}$ cells incubated with or without glutathione. Cells were first incubated with DiD-labeled liposomes, followed by the incubation of the cells with phosphate buffered saline (PBS) supplemented with $5 \%$ fetal bovine serum (FBS) (A), and with $2 \mathrm{mg} \mathrm{ml}^{-1}$ glutathione in PBS supplemented with $5 \%$ FBS (B). The left panel shows overlay images and the right panel DiD fluorescence (scale bar $=50$ $\mu \mathrm{m})$ 
A

\begin{tabular}{|c|c|c|}
\hline 10 & EL4 cells & Low CFSE label \\
\hline \multirow[b]{2}{*}{ to } & \multirow{2}{*}{ E.G7-OVA } & High CFSE label \\
\hline & & Ovalbumine presentation by MHC-I \\
\hline & \multirow{2}{*}{ OT- I CD8 } & No CFSE \\
\hline & & Ovalbumine T cell receptor \\
\hline
\end{tabular}
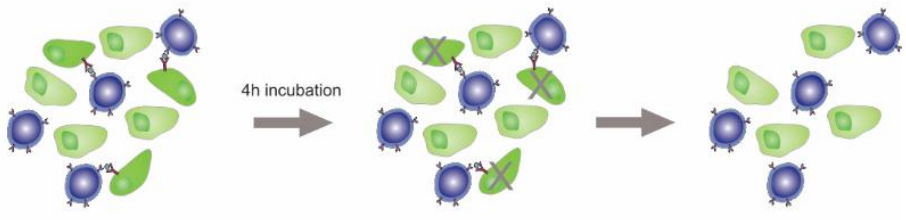

Co-culture EL4 + E.G7-OVA + OT-IT cells

Lysis of the E.G7-OVA cells
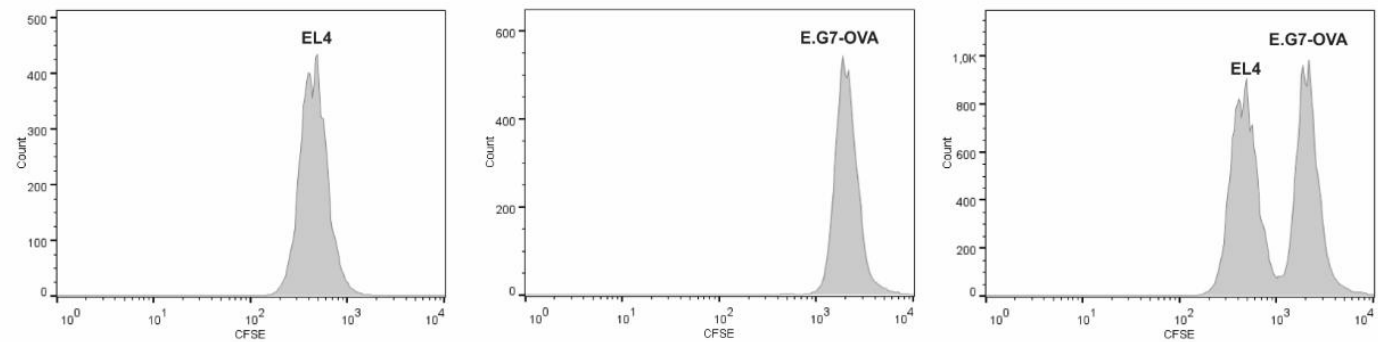

Figure S4. Co-culture of (liposome-loaded) OT-I CD8 $^{+} \mathrm{T}$ cells with E.G7-OVA target cells and EL4 control cells. (A) Schematic representation of co-culturing OT-I CD8 ${ }^{+} \mathrm{T}$ cells with EL4 control cells and E.G7-OVA target cells. E.G7-OVA and EL4 cells were labeled with a high and low CFSE concentration, respectively. Both cell types were mixed in equal amounts and incubated for $4 \mathrm{~h}$ at $37{ }^{\circ} \mathrm{C}$ with OT-I CD8 ${ }^{+} \mathrm{T}$ cells. (B) Histograms of low CFSElabeled EL4 cells, high CFSE-labeled E.G7-OVA cells, and a co-culture of EL4 and E.G7OVA cells without T cells. 
A

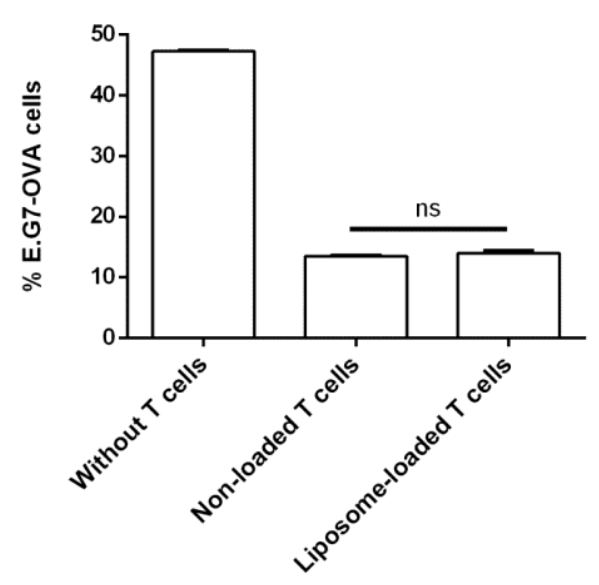

B 1:20 E:T ratio

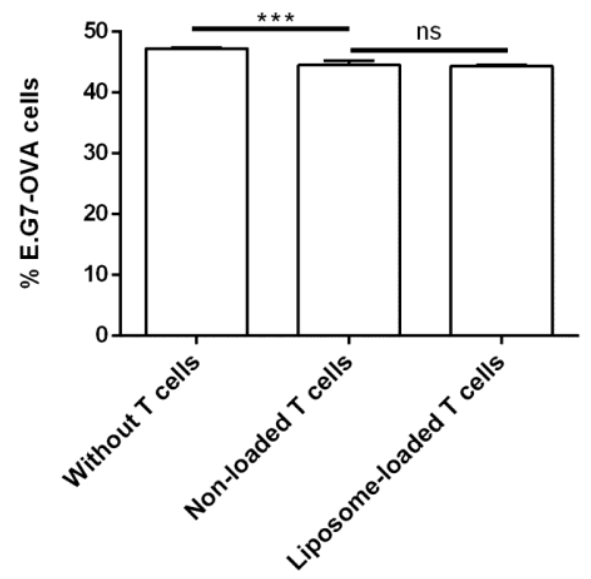

Figure S5. Percentage viable E.G7-OVA cells after the incubation with OT-I $\mathrm{CD8}^{+} \mathrm{T}$ cells. EL4 and E.G7-OVA cells were first mixed in equal amounts, followed by the $4 \mathrm{~h}$ incubation at $37{ }^{\circ} \mathrm{C}$ without OT-I T cells, with non-loaded T cells, and with liposome-loaded T cells (5 mg ml${ }^{-1}$ lipids) in a (A) 1:1 and (B) 1:20 effector:target (E:T) ratio. The E.G7-OVA and EL4 population was distinguished by their different CFSE fluorescence intensity via flow cytometry. The \% E.G7-OVA cells represented here is the E.G7-OVA cell fraction of the total population of EL4 and E.G7-OVA cells $(n=3, n s=$ not significant, $* * *=p<0.001)$. 